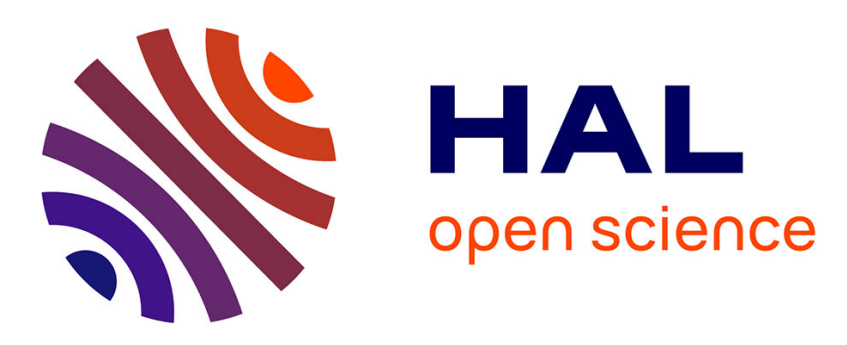

\title{
On the Stock Estimation for a Harvested Fish Population
}

\author{
Aboudramane Guiro, Abderrahman Iggidr, Diène Ngom
}

\section{To cite this version:}

Aboudramane Guiro, Abderrahman Iggidr, Diène Ngom. On the Stock Estimation for a Harvested Fish Population. Bulletin of Mathematical Biology, 2012, 74 (1), pp.116-142. 10.1007/s11538-0119667-z . inria-00523963v2

\section{HAL Id: inria-00523963 https://hal.inria.fr/inria-00523963v2}

Submitted on 26 May 2011

HAL is a multi-disciplinary open access archive for the deposit and dissemination of scientific research documents, whether they are published or not. The documents may come from teaching and research institutions in France or abroad, or from public or private research centers.
L'archive ouverte pluridisciplinaire HAL, est destinée au dépôt et à la diffusion de documents scientifiques de niveau recherche, publiés ou non, émanant des établissements d'enseignement et de recherche français ou étrangers, des laboratoires publics ou privés. 


\title{
On the Stock Estimation for a Harvested Fish Population
}

\author{
Aboudramane Guiro \\ Laboratoire d'Analyse Mathématique des Equations (LAME) \\ Faculté des Sciences et Techniques. Université de Ouagadougou \\ B.P. 7021 Ouagadougou, Burkina Faso \\ Email: Aboudramane.guiro@univ-ouaga.bf \\ ABDERRAHMAN IGGIDR \\ EPI MASAIE \\ INRIA Nancy-Grand Est and University Paul Verlaine-Metz \\ LMAM-CNRS UMR 7122, ISGMP Bat. A, Ile du Saulcy \\ 57045 Metz Cedex 01, France \\ Email: Abderrahman.Iggidr@inria.fr \\ DiÈne NGOM ${ }^{1}$ \\ UFR des Sciences et Technologies, Université de Ziguinchor \\ B.P 523 Ziguinchor, Sénégal \\ \& Laboratoire d'Analyse Numérique et d'Informatique \\ Université Gaston Berger de Saint Louis, Sénégal \\ Email: dngom@univ-zig.sn, ngomdiene@yahoo.fr
}

\begin{abstract}
We consider a stage-structured model of a harvested fish population and we are interested in the problem of estimating the unknown stock state for each class. The model used in this work to describe the dynamical evolution of the population is a discrete time system including a nonlinear recruitment relationship. To estimate the stock state, we build an observer for the considered fish model. This observer is an auxiliary dynamical system that uses the catch data over each time interval and gives a dynamical estimate of the stock state for each stage class. The observer works well even if the recruitment function in the considered model is not well known. The same problem for an age-structured model has been addressed in a previous work [26].
\end{abstract}

Keywords: Discrete-time system, Stage structured population models, Estimation, Harvested Fish Population, Observers.

\footnotetext{
${ }^{1}$ Corresponding author: dngom@univ-zig.sn, ngomdiene@yahoo.fr
} 


\section{Introduction}

Overfishing has negatively affected the stock of renewable marine resources. Analyzing the catch data during the last decade, it can be noticed that catch fishing has considerably decreased in many countries and some species are threatened with extinction. The collapse of catch fishing and the extinction of species can be explained in most cases by a gap in management policies due partly to the complex problem of controlling the dynamic evolution of marine resources. To improve the efficiency of exploiting stock and preventing the collapse of key fishery, it is essential to well understand the stock evolution mechanism and to have a good estimate of the population stock state. To overcome these types of problems in fishery management, mathematical models are very often used to describe the dynamic evolution of some fish population. With these models it becomes easier to observe and hence to regulate the dynamics of a given fish population.

In this paper, we are interested in the estimation problem of the unknown stock state of a harvested fish population whose dynamics are modeled by a discrete time system including a nonlinear stock recruitment relationship. As already mentioned in the abstract, the stock state estimation problem for a harvested fish population was first investigated [26] by considering an age-structured fishpopulation model. However determining the age for a fish population is a difficult task, it would be easier and more pertinent in practice to classify a fish population by other quantities that correlate with age such as size or weight. Moreover, most of the time the catch data that we have access to are generally evaluated in terms of size or weight. Hence a stage structured fish population model is more general and realistic than an age-structured one. The stage-structured fish model we consider here is the following (cf: [12], page 84 and 35):

$$
\left\{\begin{aligned}
x_{1}(k+1)= & \left(1-p_{1}\right) s_{1}(k) x_{1}(k)+s_{0} f\left(\sum_{i=1}^{n} b_{i} x_{i}(k)\right) \\
x_{2}(k+1)= & p_{1} s_{1}(k) x_{1}(k)+\left(1-p_{2}\right) s_{2}(k) x_{2}(k) \\
\vdots & \vdots \\
x_{n-1}(k+1)= & p_{n-2} s_{n-2}(k) x_{n-2}(k)+\left(1-p_{n-1}\right) s_{n-1}(k) x_{n-1}(k) \\
x_{n}(k+1)= & p_{n-1} s_{n-1}(k) x_{n-1}(k)+s_{n}(k) x_{n}(k)
\end{aligned}\right.
$$

where

- $n$ is the number of stage-classes.

- $x_{i}(k)$ is the number of individuals in stage class $i$ at time $k$.

- $b_{i}$ is the fecundity rate in stage class $i$.

- $s_{0}$ is the individual survival rate of newborn.

- $s_{i}(k)$ is the individual survival rate in the stage class $i$ at time $k$ :

$s_{i}(k)=e^{-M_{i}-q_{i} E(k) \tau}$ (see Getz book: pp 221) 
- $M_{i}$ is the natural mortality rate in stage class $i$.

- $q_{i}$ is the catchability coefficient of individuals in stage class $i$.

- $E(k)$ is the fishing effort at time $k$.

- $p_{i}$ is the proportion of individuals in stage class $i$ that move to the next stage class $i+1$ after the time interval $[k, k+1[$.

- $\tau$ is the length of harvesting season.

- $f$ is the stock-recruitment function.

The widely used recruitment functions $[6,12,24,30,31]$ are:

$$
\begin{array}{ll}
\text { Beverton and Holt } & f\left(x_{0}\right)=\alpha x_{0} /\left(1+\beta x_{0}\right) ; \\
\text { Ricker } & f\left(x_{0}\right)=\alpha x_{0} e^{-\beta x_{0}} ; \\
\text { Powerfunction } & f\left(x_{0}\right)=\alpha x_{0}^{1-\beta} ; \\
\text { Shepherd } & f\left(x_{0}\right)=\alpha x_{0} /\left(1+\beta x_{0}^{c}\right),(c>0) . \\
\text { Deriso-Schnute } & f\left(x_{0}\right)=\alpha x_{0}\left(1-\beta x_{0}\right)^{1 / \gamma} ; \\
\text { Saila-Lorda } & f\left(x_{0}\right)=\alpha x_{0}^{\gamma} e^{-\beta x_{0}} .
\end{array}
$$

Where $\alpha, \beta$ and $\gamma$ are positive parameters and $x_{0}=\sum_{i=1}^{n} b_{i} x_{i}$ is the number of newborns.

The recruitment function is very difficult to model because many factors such as water temperature, air speed and other natural phenomena can often perturb the growth of young individuals that are too vulnerable. One weakness of the model (1) is that most of the suggested mathematical expressions for the recruitment function are only valid for some restricted hypotheses. For example Beverton and Holt justified their recruitment function by making hypotheses on food competition whereas the Ricker recruitment function is based on eggs and juvenile predation. Hence the recruitment term in the first equation of model (1) is not well known and we can rewrite the model (1) by considering the recruitment function $s_{0} f\left(\sum_{i=1}^{n} b_{i} x_{i}(k)\right)$ as an unknown input $r(x(k))$ to obtain the linear model with unknown single input $r(x(k))$ :

$$
\left(\begin{array}{c}
x_{1}(k+1) \\
x_{2}(k+1) \\
\vdots \\
x_{n}(k+1)
\end{array}\right)=A(k)\left(\begin{array}{c}
x_{1}(k) \\
x_{2}(k) \\
\vdots \\
x_{n}(k)
\end{array}\right)+\left(\begin{array}{c}
r(x(k)) \\
0 \\
\vdots \\
0
\end{array}\right)
$$


where

$$
A(k)=\left(\begin{array}{ccccc}
\left(1-p_{1}\right) s_{1}(k) & 0 & \ldots & \ldots & 0 \\
p_{1} s_{1}(k) & \ddots & \ddots & & \vdots \\
0 & p_{2} s_{2}(k) & \ddots & \ddots & \vdots \\
\vdots & \ddots & \ddots & \left(1-p_{n-1}\right) s_{n-1}(k) & 0 \\
0 & \ldots & 0 & p_{n-1} s_{n-1}(k) & s_{n}(k)
\end{array}\right)
$$

Remark 1. Note that if $p_{i}=1$, for $i=1, \ldots, n$ we obtain the age-structured model for which we have built an observer in [26].

While we focus one analyzing a fish-population model subjected to fishing action, quantifying the number of fish catch has great importance for the synthesis of the estimator stock states. Regarding the model we address above, the number of fish catch over the time period $[k, k+1[$ in each stage class $i$ is given by:

$$
y_{i}(k)=\int_{k}^{k+\tau} q_{i} E(k) x_{i}(t) d t
$$

(cf: Getz book 's, page 146).

The total fish catch number is then:

$$
y(k)=\sum_{i=1}^{n} \int_{k}^{k+\tau} q_{i} E(k) x_{i}(t) d t
$$

After few computations we can write

$$
y(k)=\sum_{i=1}^{n} \frac{q_{i} E(k)}{q_{i} E(k)+M_{i}}\left(1-e^{\left(-M_{i}-q_{i} E(k)\right) \tau}\right) x_{i}(k)
$$

Let $C_{i}(k)=\frac{q_{i} E(k)}{q_{i} E(k)+M_{i}}\left(1-e^{\left(-M_{i}-q_{i} E(k)\right) \tau}\right)$, then $y(k)$ can be written as:

$$
y(k)=\sum_{i=1}^{n} C_{i}(k) x_{i}(k)
$$

To summarize, the model we consider in this work is:

$$
\left\{\begin{aligned}
x(k+1) & =A(k) x(k)+\operatorname{Dr}(x) \\
y(k) & =C(k) x(k)
\end{aligned}\right.
$$

where $A(k)$ is defined above, $C(k)=\left(C_{1}(k), \ldots, C_{n}(k)\right)$ and $D=(1,0, \ldots, 0)^{t}$. 
Now we assume that the model with unknown single input (2), which can be written as (7), describes successfully the dynamics of the considered harvested fish population. To compute the state $x(k)$ at time $k$, we need to know the value of the state $x\left(k_{0}\right)$ at a given time $k_{0}<k$. However the model does not give any information about the unknown state value $x\left(k_{0}\right)$. The model only provides information about relation between two consecutive states $x(k)$ and $x(k+1)$. The model also gives measure of captures over time interval $[k, k+1$ [. To make the model (2) useful, we have to find how to estimate the unknown value $x(k)$. This is the main concern we will address in this paper. To achieve this goal, we will use a tool from control theory called observer. We construct another dynamical system whose state $\hat{x}$ will provide an estimate of the unknown state of the considered model and this will be true regardless of the initial condition of the observer. We briefly recall the definition of an observer in control theory. Let us consider the following dynamic system:

$$
\left\{\begin{array}{l}
x(k+1)=\mathcal{F}(x(k), u(k)) \\
y(k)=\mathcal{H}(x(k), u(k)) .
\end{array}\right.
$$

where $x(k) \in \mathbb{R}^{n}$ is the state of the system , $u(k) \in U \subset \mathbb{R}^{m}$ is the input or the control and $y(k) \in \mathbb{R}^{q}$ is the measurable output at time $k$.

Definition 1. An observer for the dynamical system (8) is another dynamical system $\Sigma$ whose inputs are the inputs and the outputs of system (8) and whose state $\hat{x}(k)$ satisfies $x(k)-\hat{x}(k)$ tends to zero as time $k$ goes to infinity and must remain small if it starts small.

$\Sigma$ is an exponential observer of (8) if there exists $\rho<1$ in such a way that for all $k \geq 0$ and for all initial conditions $(x(0), \hat{x}(0))$, one has

$$
|\hat{x}(k)-x(k)| \leq \rho^{k}|\hat{x}(0)-x(0)|
$$

Usually, a candidate observer $\Sigma$ for system (8) is given by

$$
\left\{\begin{array}{l}
z(k+1)=\mathcal{G}(x(k), u(k), y(k)), \\
\hat{x}(k)=\mathcal{J}(z(k), y(k)) .
\end{array}\right.
$$

More details on observer notions can be found in [16, 34]. Observer theory for linear discrete-time system with known inputs is well established. For linear invariant-time systems, the synthesis of the observer is completely given by the Luenberger method [23]. For linear time varying systems, several robust algorithms have been developed, one can cite for instance [1, 3, 5, 8, 20, 21]. In the special case of uncertain systems the synthesis of observers is still a very difficult task. The Kalman filter [2] is the most classical approach used to build observers for uncertain systems but the optimal filter require restricted hypothesis. Another approach which is based on dynamical interval analysis exists in the literature [9, 29], the idea consist in computing an interval known as "interval observer" which contains the state variable we need to estimate. Several algorithms on the synthesis of "interval observer" has been proposed in the literature for continuous systems $[22,28]$ and for discrete-time system [17, 32]. Some algorithms have also been developed to solve 
the estimation problem for some classes of system with unknown inputs [7, 10, 13, 14, 15, 18, 19, 27, 33, 35]. Some of these observers carry out only the system state estimation, while other observers allow the estimation of the states as well as the unknown inputs of the system. One of the techniques used for the synthesis of the observer that estimate the states and the unknown inputs of a system consists in regrouping the state vector and the unknown inputs of the system in an augmented state-vector and in building an estimator for this augmented system [15, 19, 37]. To construct an observer for system with unknown inputs, one can use an approach that consists in eliminating the unknowns inputs in the equations of the system [14]. However, most of the

available results concern linear time invariant systems. Here we are interested in the design of a global observer for the fishery system (2) which is a linear time varying system with known input $E(k)$ and unknown input $r(x(k))$.

\section{Observer for linear time varying systems with unknown inputs}

We consider the following time-varying system:

$$
\left\{\begin{aligned}
x(k+1) & =\Gamma(k) x(k)+\Lambda \zeta, \\
y(k) & =\theta(k) x(k),
\end{aligned}\right.
$$

where $x(k)$ and $y(k)$ are respectively the state and the measurable output at time $k, \Gamma(k)$ and $\theta(k)$ are respectively time varying matrix, $\Lambda$ is a column vector and $\zeta$ is a scalar unknown input. In [13] M. Hou and P.C. Muller have developed a technique to synthesize observers for linear continuous time-invariant systems with unknown inputs. We adapt this technique for linear discrete timevarying systems with unknown inputs of the form (10).

Let $y(k)$ be the measurable output of the system (10), we have

$$
\begin{aligned}
y(k+1) & =\theta(k+1) x(k+1) \\
& =\theta(k+1)(\Gamma(k) x(k)+\Lambda \zeta) \\
& =\theta(k+1) \Gamma(k) x(k)+\theta(k+1) \Lambda \zeta
\end{aligned}
$$

Assume that $\theta(k+1) \Lambda$ is invertible $\forall k \geq 0$. Thus we obtain:

$$
\zeta=(\theta(k+1) \Lambda)^{-1}(y(k+1)-\theta(k+1) \Gamma(k) x(k))
$$

Then we have:

$$
\begin{aligned}
x(k+1) & =\Gamma(k) x(k)+\Lambda \zeta \\
& =\Gamma(k) x(k)+\Lambda\left((\theta(k+1) \Lambda)^{-1}(y(k+1)-\theta(k+1) \Gamma(k) x(k))\right) \\
& =\Gamma(k) x(k)+\Lambda(\theta(k+1) \Lambda)^{-1} y(k+1)-\Lambda(\theta(k+1) \Lambda)^{-1} \theta(k+1) \Gamma(k) x(k) \\
& =\left(\Gamma(k)-\Lambda(\theta(k+1) \Lambda)^{-1} \theta(k+1) \Gamma(k)\right) x(k)+\Lambda(\theta(k+1) \Lambda)^{-1} y(k+1) \\
& =\left(I_{n \times n}-\Lambda(\theta(k+1) \Lambda)^{-1} \theta(k+1)\right) \Gamma(k) x(k)+\Lambda(\theta(k+1) \Lambda)^{-1} y(k+1) .
\end{aligned}
$$


We define:

$$
\bar{\Gamma}(k)=\left(I_{n \times n}-\Lambda(\theta(k+1) \Lambda)^{-1} \theta(k+1)\right) \Gamma(k) .
$$

Thus we obtain:

$$
x(k+1)=\bar{\Gamma}(k) x(k)+\Lambda(\theta(k+1) \Lambda)^{-1} y(k+1)
$$

A candidate observer for system (10) is then given by:

$$
\begin{cases}z(k+1) & =(\bar{\Gamma}(k)-L(k) \theta(k)) z(k)+\left(L(k)+(\bar{\Gamma}(k)-L(k) \theta(k)) \Lambda(\theta(k) \Lambda)^{-1}\right) y(k) . \\ \hat{x}(k) & =z(k)+\Lambda(\theta(k) \Lambda)^{-1} y(k) .\end{cases}
$$

Let $e(k)=x(k)-\hat{x}(k)$ the estimation error, the error dynamics are described by:

$$
\begin{aligned}
e(k+1) & =x(k+1)-\hat{x}(k+1) \\
& =\bar{\Gamma}(k) x(k)+\Lambda(\theta(k+1) \Lambda)^{-1} y(k+1)-z(k+1)-\Lambda(\theta(k+1) \Lambda)^{-1} y(k+1) \\
& =\bar{\Gamma}(k) x(k)-(\bar{\Gamma}(k)-L(k) \theta(k)) z(k)-\left(L(k)+(\bar{\Gamma}(k)-L(k) \theta(k)) \Lambda(\theta(k) \Lambda)^{-1}\right) y(k) \\
& =(\bar{\Gamma}(k)-L(k) \theta(k)) x(k)-(\bar{\Gamma}(k)-L(k) \theta(k)) z(k) \\
& -(\bar{\Gamma}(k)-L(k) \theta(k)) \Lambda(\theta(k) \Lambda)^{-1} y(k) \\
& =(\bar{\Gamma}(k)-L(k) \theta(k))(x(k)-\hat{x}(k)) \\
e(k+1) & =(\bar{\Gamma}(k)-L(k) \theta(k)) e(k)
\end{aligned}
$$

To summarize, we have the following result

Proposition 1. Assume that the matrix $\theta(k) \Lambda$ is invertible for all $k$. If there exists a matrix $L(k)$ in such a way that the matrix $\bar{\Gamma}(k)-L(k) \theta(k)$ satisfies $\|\bar{\Gamma}(k)-L(k) \theta(k)\| \leq \delta$ for some $\delta<1$ then system (11) is a global exponential observer for system (10), i.e., the estimation error e $(k)$ tends exponentially fast towards zero as $k$ tends to $+\infty$.

A sufficient condition for the existence of such a matrix $L(k)$ is that the pair $[\bar{\Gamma}(k), \theta(k)]$ is uniformly observable. We recall here what does uniform observability mean. Consider the system $x(k+1)=\bar{\Gamma}(k) x(k)$ with measurable output $y(k)=\theta(k) x(k)$. Let $\Psi_{i, k}$ for $i \geq k$ be the transition matrix for the system $x(k+1)=\bar{\Gamma}(k) x(k)$, i.e.

$$
\Psi_{i, i}=I_{n \times n} \text { and } \Psi_{i, k}=\bar{\Gamma}(i-1) \bar{\Gamma}(i-2) \ldots \bar{\Gamma}(k) \text { for } i>k \text {. }
$$

The observability Gramian for the system is defined as

$$
G_{k+t, k}=\sum_{i=k}^{k+t} \Psi_{i, k}^{T} \theta(i)^{T} \theta(i) \Psi_{i, k}\left(\text { where } A^{T} \text { is the transpose matrix of } A\right. \text { ). }
$$


The pair $[\bar{\Gamma}(k), \theta(k)]$ is uniformly observable if there exist a positive real $\beta>0$ and a positive integer $t>0$ such that one has for all $k \geq 0$

$$
G_{k+t, k} \geq \beta I_{n \times n}
$$

If the pair $[\bar{\Gamma}(k), \theta(k)]$ is uniformly observable and the matrices $\bar{\Gamma}(k), \theta(k)$ are bounded above then a possible choice for the gain matrix $L(k)$ that makes the error equation $e(k+1)=(\bar{\Gamma}(k)-$ $L(k) \theta(k)) e(k)$ globally exponentially stable is given by the following formula (see [25] for instance):

$$
L(k)=\bar{\Gamma}(k) \Psi_{k, k-t-1} G_{k, k-t-1}^{-1} \Psi_{k, k-t-1}^{T} \theta(k)^{T}
$$

\section{Stock state estimation using an observer}

In this section we shall apply the method developed in Section 2 in order to construct an observer that will provide an estimate of the state of system (2) using only the measurable output given by equation (5).

System (7) has the same form as system (10) with:

$$
\Gamma(k)=A(k), \quad \Lambda=D, \quad \zeta=r(x(k)) \quad \text { and } \quad \theta(k)=C(k)
$$

We assume that $q_{1} \neq 0$. Therefore $C(k) D=C_{1}(k)=\frac{q_{1} E(k)}{q_{1} E(k)+M_{1}}\left(1-e^{\left(-M_{1}-q_{1} E(k)\right)_{\tau}}\right) \neq 0$ for all $k>0$, so that $C(k) D$ is invertible for all $k>0$.

As in Section 2 we define:

$$
\bar{A}(k)=\left(I_{n \times n}-D(C(k+1) D)^{-1} C(k+1)\right) A(k)=\left(I_{n \times n}-\frac{1}{C_{1}(k+1)} D C(k+1)\right) A(k) .
$$

Therefore a candidate observer for system (2) (or system (7)) is given by:

$$
\begin{cases}z(k+1) & =(\bar{A}(k)-L(k) C(k)) z(k)+\left(L(k)+(\bar{A}(k)-L(k) C(k)) D(C(k) D)^{-1}\right) y(k) \\ \hat{x}(k) & =z(k)+D(C(k) D)^{-1} y(k)\end{cases}
$$

To compute the appropriate matrix gain $L(k)$, one can uses the formula (13). However, one has first to check the uniform observability of the pair $[\bar{A}(k), C(k)]$ which is not an easy task due to the large number of parameters and when the condition (12) is satisfied, the formula (13) gives a huge expression for the matrix $L(k)$. These computations can be done when the parameter numerical values as well as the expression of the fishing effort are available. But here we prefer to give a simple expression for the observer, so, instead of computing $L(k)$, we just choose $L(k)=0$ and impose a weak condition on the fishing effort in such a way that the estimation error equation $e(k+1)=\bar{A}(k) e(k)$ is exponentially stable. Therefore the candidate observer (14) becomes: 


$$
\begin{cases}z(k+1) & =\bar{A}(k) z(k)+\bar{A}(k) D(C(k) D)^{-1} y(k)=\bar{A}(k) z(k)+\bar{A}(k) D \frac{y(k)}{C_{1}(k)} \\ \hat{x}(k) & =z(k)+D(C(k) D)^{-1} y(k)\end{cases}
$$

This can be written in a more detailed form:

$$
\left\{\begin{aligned}
z_{1}(k+1)= & -\frac{C_{2}(k+1) p_{1} s_{1}(k)}{C_{1}(k+1)} z_{1}(k) \\
& -\sum_{i=2}^{n-1}\left(p_{i} s_{i}(k) \frac{C_{i+1}(k+1)}{C_{1}(k+1)}+\left(1-p_{i}\right) s_{i}(k) \frac{C_{i}(k+1)}{C_{1}(k+1)}\right) z_{i}(k) \\
& -\frac{C_{n}(k+1) s_{n}(k)}{C_{1}(k+1)} z_{n}(k)-\frac{C_{2}(k+1) p_{1} s_{1}(k)}{C_{1}(k+1) C_{1}(k)} y(k) \\
z_{2}(k+1)= & p_{1} s_{1}(k) z_{1}(k)+\left(1-p_{2}\right) s_{2}(k) z_{2}(k)+\frac{p_{1} s_{1}(k)}{C_{1}(k)} y(k), \\
z_{3}(k+1)= & p_{2} s_{2}(k) z_{2}(k)+\left(1-p_{3}\right) s_{3}(k) z_{3}(k), \\
\vdots & \vdots \\
z_{n-1}(k+1)= & p_{n-2} s_{n-2}(k) z_{n-2}(k)+\left(1-p_{n-1}\right) s_{n-1}(k) z_{n-1}(k), \\
z_{n}(k+1)= & p_{n-1} s_{n-1}(k) z_{n-1}(k)+s_{n}(k) z_{n}(k), \\
\hat{x}_{1}(k)= & z_{1}(k)+\frac{1}{C_{1}(k)} y(k), \\
\hat{x}_{i}(k)= & z_{i}(k) \text { for } i=2, \ldots n .
\end{aligned}\right.
$$

We define: $E_{\text {min }} \leq E(k) \leq E_{\max }$ for all $k \geq 0, q_{\min } \leq q_{i} \leq q_{\max }$ and $M_{\min } \leq M_{i} \leq M_{\max }$ for all $i=1, \ldots, n$. Our main result can be written:

Proposition 2. Assume that $q_{1} \neq 0$. There exists $\eta>0$ such that if $E_{\text {min }}>\eta$, then the system (15) (or system (16)) is a global exponential observer for system (2): the estimation error satisfies $|\hat{x}(k)-x(k)| \leq \delta^{k}|\hat{x}(0)-x(0)|$ for all $k \geq 0$, with

$$
\begin{aligned}
\delta=\delta\left(E_{\min }\right) & =\left(\frac{M_{\max } q_{\max }}{q_{1}} \frac{1}{M_{\min }+q_{\min } E_{\min }}+\frac{1}{1-e^{-\left(M_{\min }+q_{\min } E_{\min }\right) \tau}}+1\right) e^{-\left(M_{\min }+q_{\min } E_{\min }\right) \tau} \\
& <1 \text { if } E_{\min }>\eta .
\end{aligned}
$$

Proof. See the Appendix A.

Remark 2. The convergence rate of the observer (16) is less or equal than $\delta\left(E_{\text {min }}\right)$. It can not be adjusted.

Remark 3. When the coefficients $p_{i}$ are all equal to 1 , the model (2) is equivalent to the age structured fish model (see for instance [12]) for which an observer has been built in [26]. 
Remark 4. When the natural mortality rates are all equal, it is possible to give a weaker condition on the minimal value of the fishing effort that ensures the convergence of the observer.

Proposition 3. Assume that $q_{1} \leq q_{i} \forall i=2, \ldots, n$, and moreover that the natural mortality coefficient is the same for all stages, that is, $M_{1}=M_{2}=\ldots=M_{n}=M$. Then, the system (16) is a global exponential observer for the system (2) if

$$
E_{\text {min }}>\frac{1}{q_{1}}\left(\frac{1}{\tau} \log \left[\frac{q_{\max }}{q_{1}}+1\right]-M\right) .
$$

Remark 5. The available catch data usually give the seasonal biomass yield, i.e., the total weight of the fishes caught during a season. If we denote $w_{i}$ the mean weight of individuals of stage $i$, $m_{i}(k)$ the biomass of stage $i$ at time $k$ and $F_{i}(k)=q_{i} E(k)$ the fishing mortality rate for stage $i$, then the measurable output (seasonal biomass yield) can be expressed as follows:

$$
\begin{aligned}
Y(k) & =\sum_{i=1}^{n} \frac{F_{i}(k)}{M_{i}+F_{i}(k)}\left(1-e^{\left(-M_{i}-F_{i}(k)\right) \tau}\right) w_{i} x_{i}(k) \\
& =\sum_{i=1}^{n} \frac{F_{i}(k)}{M_{i}+F_{i}(k)}\left(1-e^{\left(-M_{i}-F_{i}(k)\right) \tau}\right) m_{i}(k) \\
& =\sum_{i=1}^{n} C_{i}(k) m_{i}(k)
\end{aligned}
$$

The equation (16) of the observer can be modified in order to estimate the biomass $m_{i}(k)=w_{i} x_{i}(k)$ for each stage instead of the number of individuals in each stage by replacing in (16) y(k) by $Y(k)$ and $\hat{x}_{i}(k)$ by $\hat{m}_{i}(k)$.

\section{Numerical example}

We now give some simulations to illustrate the efficiency of the observer (16). We suppose that the dynamics of a harvested population can be modeled by a three-stages model with a Ricker stock-recruitment function:

$$
\left\{\begin{array}{l}
x_{1}(k+1)=\left(1-p_{1}\right) s_{1}(k) x_{1}(k)+\alpha \sum_{i=1}^{3} b_{i} x_{i}(k) e^{-\beta\left(\sum_{i=1}^{3} b_{i} x_{i}(k)\right)} \\
x_{2}(k+1)=p_{1} s_{1}(k) x_{1}(k)+\left(1-p_{2}\right) s_{2}(k) x_{2}(k) \\
x_{3}(k+1)=p_{2} s_{2}(k) x_{2}(k)+s_{3}(k) x_{3}(k)
\end{array}\right.
$$

We assume that the biological parameter values as well as the fishing strategy are known and are given by:

$\begin{array}{ll}\text { Parameters of the Ricker function } & \alpha=1, \beta=0.0002, \\ \text { Fecundity parameters } & b=\left[\begin{array}{lll}2 & 5 & 7\end{array}\right], \\ \text { Catchability coefficients } & q=\left[\begin{array}{lll}0.24 & 0.36 & 0.42\end{array}\right], \\ \text { Natural mortality rates } & M=\left[\begin{array}{lll}0.2 & 0.2 & 0.2\end{array}\right], \\ \text { Transfer coefficients } & p_{1}=0.1, p_{2}=0.2 \\ \text { Length of harvesting season } & \tau=1 / 2, \\ \text { Fishing effort } & E(k)=3+\sin (k)\end{array}$


Recall that since the value of $\left(x_{1}(0), x_{2}(0), x_{3}(0)\right)$ is not known, one can not use system (18) to evaluate $\left(x_{1}(k), x_{2}(k), x_{3}(k)\right)$ for a given positive time $k$. It is reasonable to assume that the value of the total catch is available for each fishing season, that is, the value of the quantity $y(k)=$ $\sum_{i=1}^{3} \frac{q_{i} E(k)}{q_{i} E(k)+M_{i}}\left(1-e^{\left(-M_{i}-q_{i} E(k)\right) \tau}\right) x_{i}(k)=\sum_{i=1}^{3} C_{i}(k) x_{i}(k)$ is known for each $k$. Therefore the observer (16) which uses the value of the total catch can be used to give a dynamical estimation of the stock state because we have proved in Section 3 that its solutions will converge (quite rapidly) towards the solutions of the model (18) regardless of the value of the initial conditions. Moreover, this observer can be implemented without using the expression of the recruitment function. To summarize, if the value of the total catch is available for each season then a good estimate $\left(\hat{x}_{1}(k), \hat{x}_{2}(k), \hat{x}_{3}(k)\right)$ of the stock state $\left(x_{1}(k), x_{2}(k), x_{3}(k)\right)$ can be obtained by choosing an arbitrary initial condition $\left(z_{1}(0), z_{2}(0), z_{3}(0)\right)$ and computing the solutions of the following observer:

$$
\left\{\begin{aligned}
z_{1}(k+1)= & -\frac{C_{2}(k+1) p_{1} s_{1}(k)}{C_{1}(k+1)} z_{1}(k) \\
& -\left(p_{2} s_{2}(k) \frac{C_{3}(k+1)}{C_{1}(k+1)}+\left(1-p_{2}\right) s_{2}(k) \frac{C_{2}(k+1)}{C_{1}(k+1)}\right) z_{2}(k) \\
& -\frac{C_{3}(k+1) s_{3}(k)}{C_{1}(k+1)} z_{3}(k)-\frac{C_{2}(k+1) p_{1} s_{1}(k)}{C_{1}(k+1) C_{1}(k)} y(k) \\
z_{2}(k+1)= & p_{1} s_{1}(k) z_{1}(k)+\left(1-p_{2}\right) s_{2}(k) z_{2}(k)+\frac{p_{1} s_{1}(k)}{C_{1}(k)} y(k), \\
z_{3}(k+1)= & p_{2} s_{2}(k) z_{2}(k)+s_{3}(k) z_{3}(k), \\
\hat{x}_{1}(k)= & z_{1}(k)+\frac{1}{C_{1}(k)} y(k), \\
\hat{x}_{i}(k)= & z_{i}(k) \text { for } i=2,3 .
\end{aligned}\right.
$$

We have plotted the solutions of systems (18) and (19) using arbitrary initial conditions. The Figures (1), (2) and (3) confirm the fact that the $\hat{x}_{i}(k)$ (dashed curves) delivered by the observer (19) are good estimates of the states $x_{i}(k)$ of system (18). It can be noticed that the convergence of the state estimates $\hat{x}_{i}(k)$ towards the real states $x_{i}(k)$ is quite fast. 


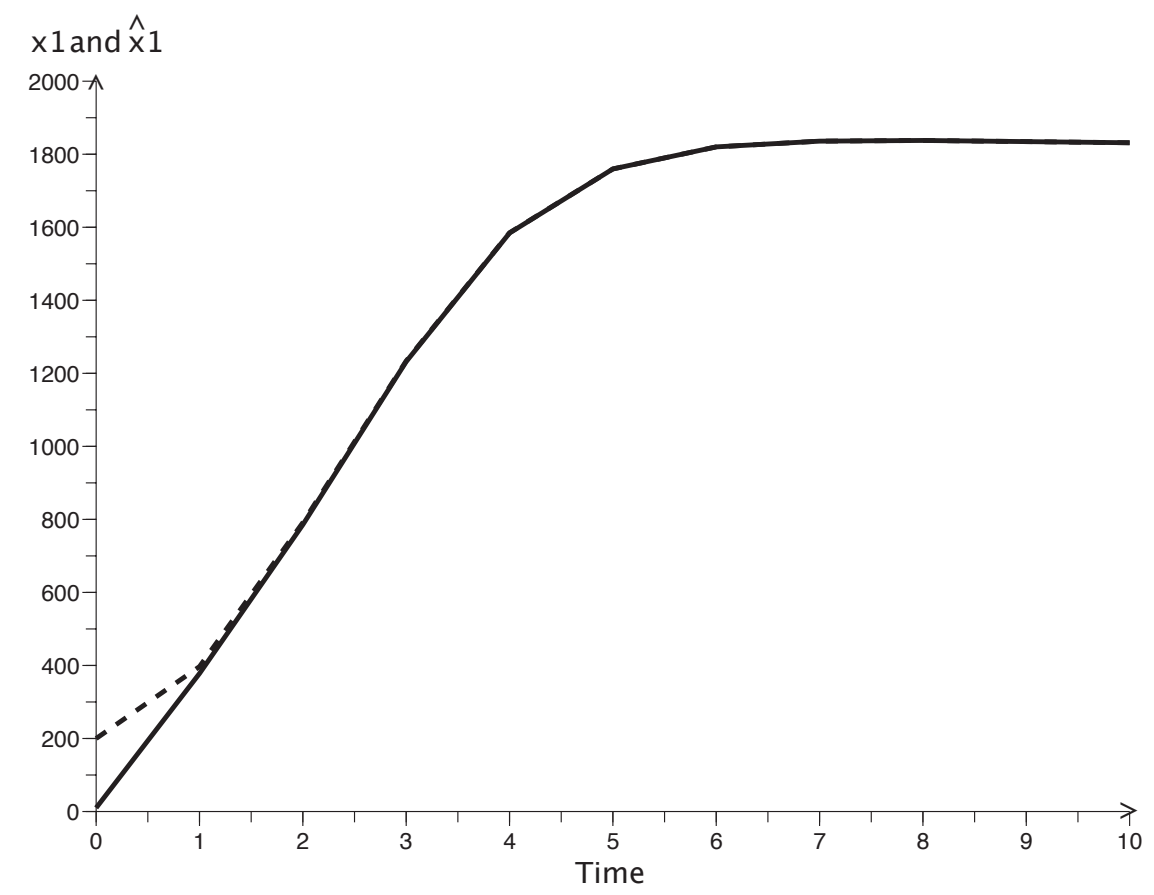

Figure 1: State $x_{1}$ (solid line) and the corresponding estimate $\hat{x}_{1}$ (dashed line) delivered by the observer (19)

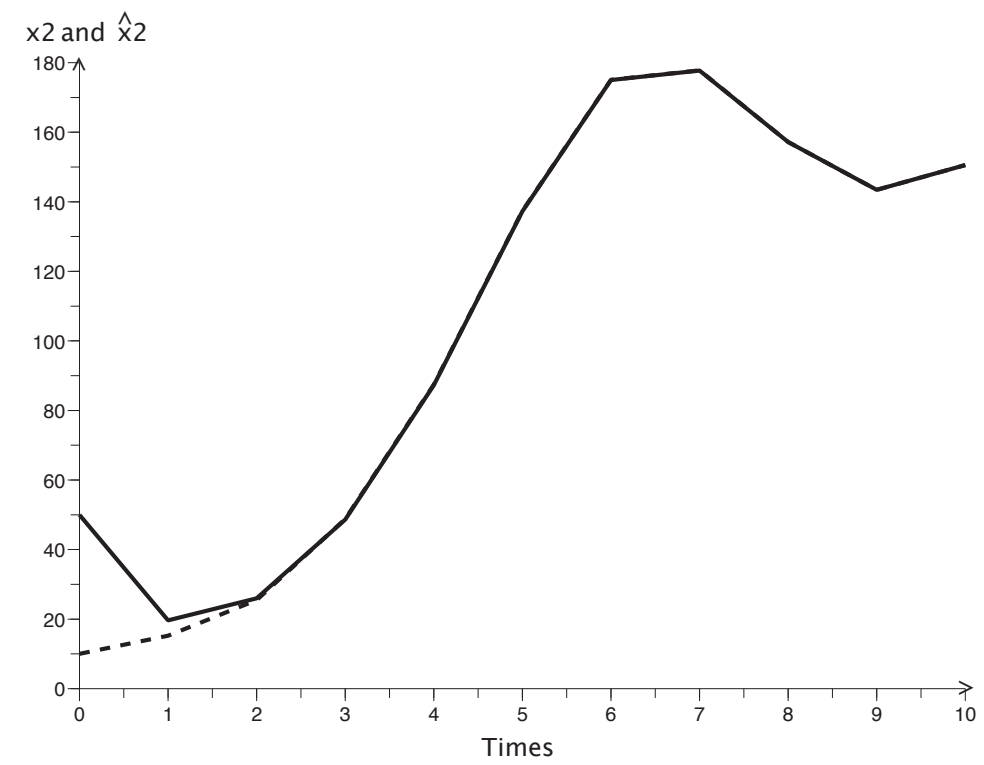

Figure 2: State $x_{2}$ (solid line) and the corresponding estimate $\hat{x}_{2}$ (dashed line) delivered by the observer (19) 


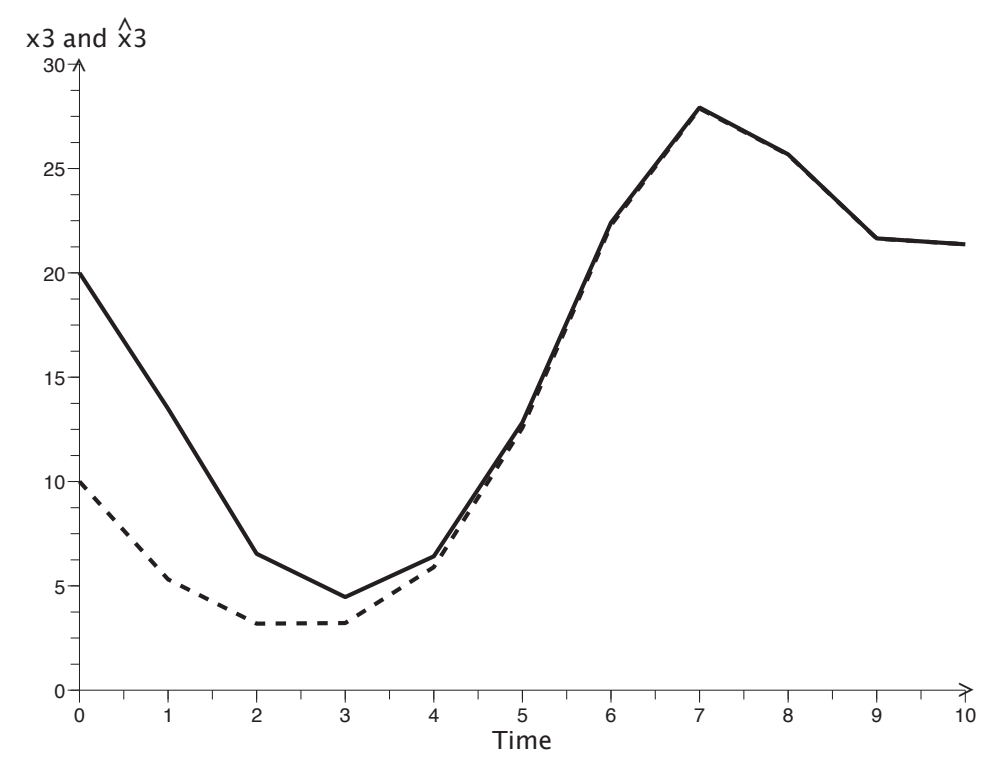

Figure 3: State $x_{3}$ (solid line) and the corresponding estimate $\hat{x}_{3}$ (dashed line) delivered by the observer (19)

\section{Applications}

\subsection{Application using data from ICES}

Now we shall illustrate how to use the the observer (16) with real data assessed by the Advisory Committee on Fisheries Management (ACFM) of the International Council for the Exploration of the Sea (ICES). One of the major task of the ICES is to collect scientific information in order to give advice to decision makers about the question of fisheries conservation and protection of the marine environment. In this context, the Advisory Committee on Fisheries Management of ICES has published a report on the evolution of the stock of the Arctic cod in the Atlantic North East [4] (see also [36]) between 1946 and 2000. The annual stock for immature and mature of the considered fish population between 1946 and 2000 are estimated in this report.

This report (Table 1) gives for each year:

- total catch of immature individuals $\left(Y_{1}(k)\right)$;

- total catch of mature individuals $\left(Y_{2}(k)\right)$;

- fishing mortality rate for immature $\left(F_{1}(k)\right)$ and for mature individuals $\left(F_{2}(k)\right)$;

- the ICES annual stock estimates $m_{1}(k)$ for immature and $m_{2}(k)$ for mature.

In order to give an application of the proposed observer with these data we will consider the observer (16) with two classes $(n=2)$ : the class of immature and the class of mature individuals. 
Using Table 1, we compute for each year $k$ the measurable output $y(k)$ which is the total catch of mature and immature individuals at year $k$, i.e., $Y(k)=Y_{1}(k)+Y_{2}(k)$. Table 1 also gives the values of the fishing mortality rates $F_{1}(k)$ and $F_{2}(k)$. The ICES assumes a natural mortality rate $M_{1}=M_{2}=M=0.2$ and $\tau=1$ (the length of harvesting season). The proportion $p_{1}$ of immature individuals that move into the mature stage class at time $k+1$ has been chosen equal to $p_{1}=0.1$. Therefore, for all $k$, Table 1 allows to compute $Y(k), C_{i}(k)=\frac{F_{i}(k)}{M_{i}+F_{i}(k)}\left(1-e^{-\left(M_{i}+F_{i}(k)\right)}\right)$, and $s_{i}(k)=e^{-\left(M_{i}+F_{i}(k)\right)}$. Hence with all these data, it is possible to run the following observer (20) that will deliver stock estimates $\hat{x}_{1}(k)$ and $\hat{x}_{2}(k)$ for immature and mature individuals:

$$
\left\{\begin{array}{l}
z_{1}(k+1)=-\frac{C_{2}(k+1) p_{1} s_{1}(k)}{C_{1}(k+1)} z_{1}(k)-\frac{C_{2}(k+1)}{C_{1}(k+1)} s_{2}(k) z_{2}(k)-\frac{C_{2}(k+1) p_{1} s_{1}(k)}{C_{1}(k+1) C_{1}(k)} Y(k), \\
z_{2}(k+1)=p_{1} s_{1}(k) z_{1}(k)+s_{2}(k) z_{2}(k)+\frac{p_{1} s_{1}(k)}{C_{1}(k)} Y(k), \\
\hat{m}_{1}(k)=z_{1}(k)+\frac{1}{C_{1}(k)} Y(k), \\
\hat{m}_{2}(k)=z_{2}(k) .
\end{array}\right.
$$

To compare our estimations with those of ICES Advisory Committee on fisheries Management, we represent in the same graphs 4 and 5 the two estimations. These graphs show that our estimations have the same behavior as those of the ICES Advisory Committee on fisheries Management. Our observer slightly overestimates the biomass state for immature class. 


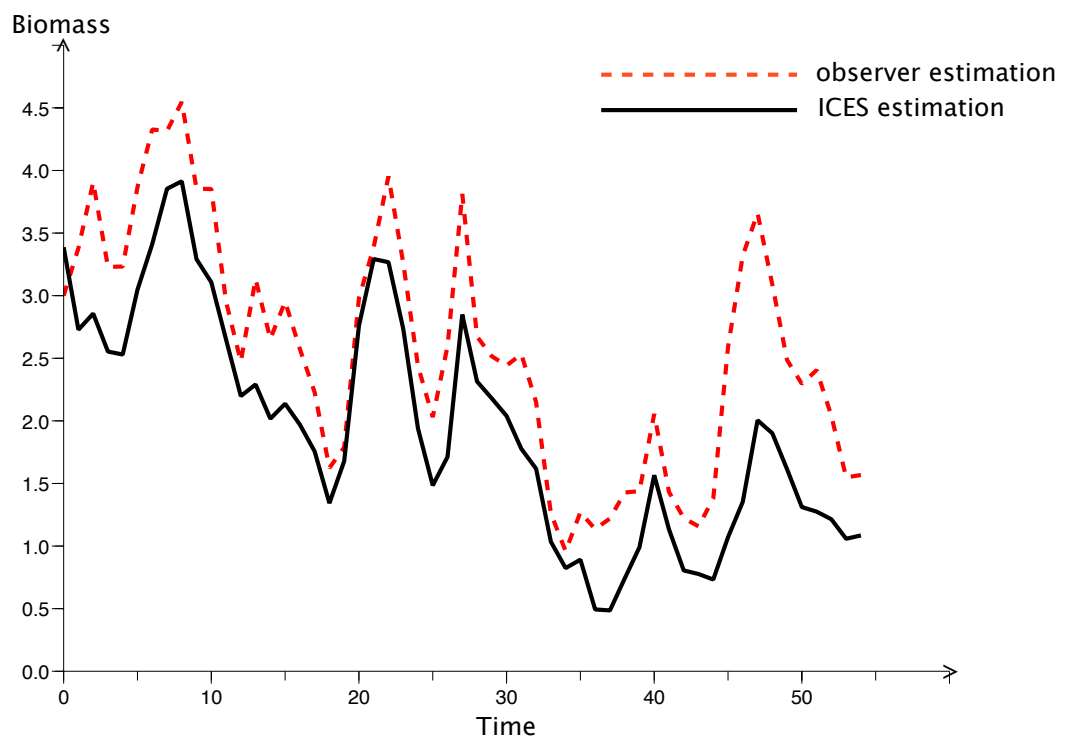

Figure 4: ICES biomass estimates and observer biomass estimates for the immature class.

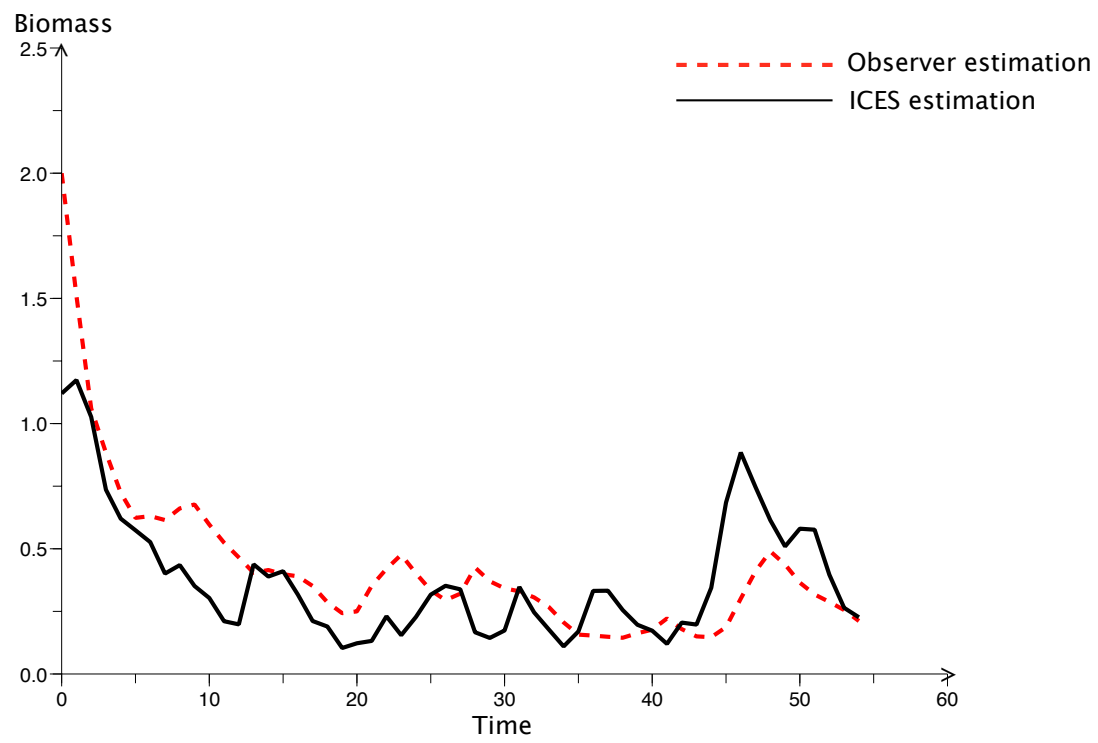

Figure 5: ICES biomass estimates and observer biomass estimates for the mature class. 


\subsection{Application using FAO data}

As we mentioned it in Remark 1, when all the parameters $p_{i}, i=1, \ldots, n$ are assumed to be equal to one, the model (2) becomes:

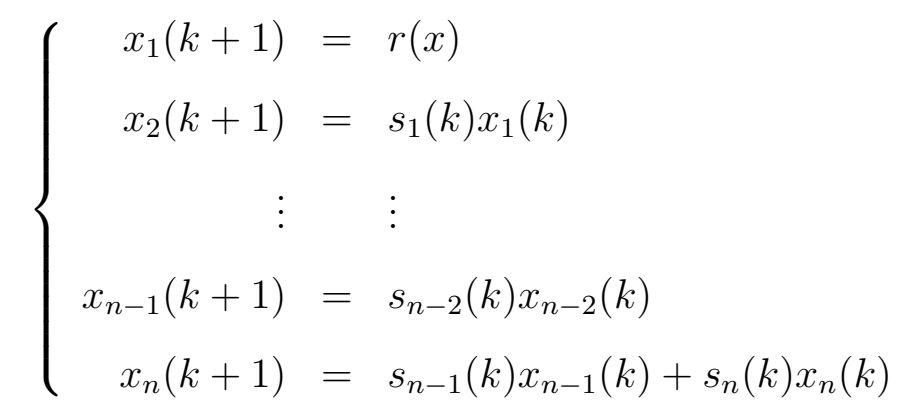

which is exactly the corresponding age structured model (see for instance [12]), than the observer becomes:

$$
\left\{\begin{aligned}
& z_{1}(k+1)=-\frac{C_{2}(k+1) s_{1}(k)}{C_{1}(k+1)} z_{1}(k)-\sum_{i=2}^{n-1} s_{i}(k) \frac{C_{i+1}(k+1)}{C_{1}(k+1)} z_{i}(k) \\
&-\frac{C_{n}(k+1) s_{n}(k)}{C_{1}(k+1)} z_{n}(k)-\frac{C_{2}(k) s_{1}}{C_{1}(k)^{2}} y(k) \\
&= s_{1}(k) z_{1}(k)+\frac{s_{1}}{C_{1}(k)} y(k), \\
& z_{2}(k+1)= \vdots \\
& \vdots s_{n-2}(k) z_{n-2}(k), \\
& z_{n-1}(k+1)= s_{n-1}(k) z_{n-1}(k)+s_{n}(k) z_{n}(k) \\
& z_{n}(k+1)= z_{1}(k)+\frac{1}{C_{1}(k)} y(k), \\
& \hat{x}_{1}(k)= z_{i}(k) \text { for } i=2, \ldots n . \\
& \hat{x}_{i}(k)=
\end{aligned}\right.
$$

where $C_{i}(k)=\frac{F_{i}(k)}{F_{i}(k)+M_{i}}\left(1-e^{\left(-M_{i}-F_{i}(k)\right) \tau}\right)$ and $s_{i}(k)=e^{\left(-M_{i}-F_{i}(k)\right) \tau}$

As in the previous section we give an application of the observer (22) using data from the the United Nations Food and Agriculture Organization of (FAO). These data are presented in the report [11]. This report concerned the stock estimation of the chinchards Trachurus spp in the statistical division COPAGE 34.1.3 and 34.3.1 which is a part of the Atlantic Eastern central ocean. The chinchards Trachurus spp population is classified into eight age-classes (class $0^{+}, 1,2,3,4,5,6,7^{+}$) and the annual commercial catches $y_{i}(k)$ in each age-class between 1972 and 1985 are given in Table 2. Most of the the annual commercial catches of the age-class $0^{+}$are null. So we assume that the age-class 1 is the recruitment class and hence the harvested fishes correspond to the 
age-classes $1,2,3,4,5,6,7^{+}$. The natural mortality rates $M_{i}$ are assumed to be all equal to 0.5 , the fishing mortality rates $F_{i}(k)$ for each age-class are given in Table 3.

Using the data contained in the Tables 2 and 3 one can implement the observer (22) and compare the estimates delivered by this observer with the FAO estimates given by Table 4 . It should be noticed that we only need the value of the total catch which is easier to measure than the catch for each age-class. The observer is implemented with two arbitrary different initial conditions to show that this initial condition didn't impact the convergence of the observer toward the "real states" of the stock. In Figures 6, 7, 8, 9, 10, 11 and 12 we compare the FAO stock estimates and the corresponding estimates computed by the observer (22) for each age-class.

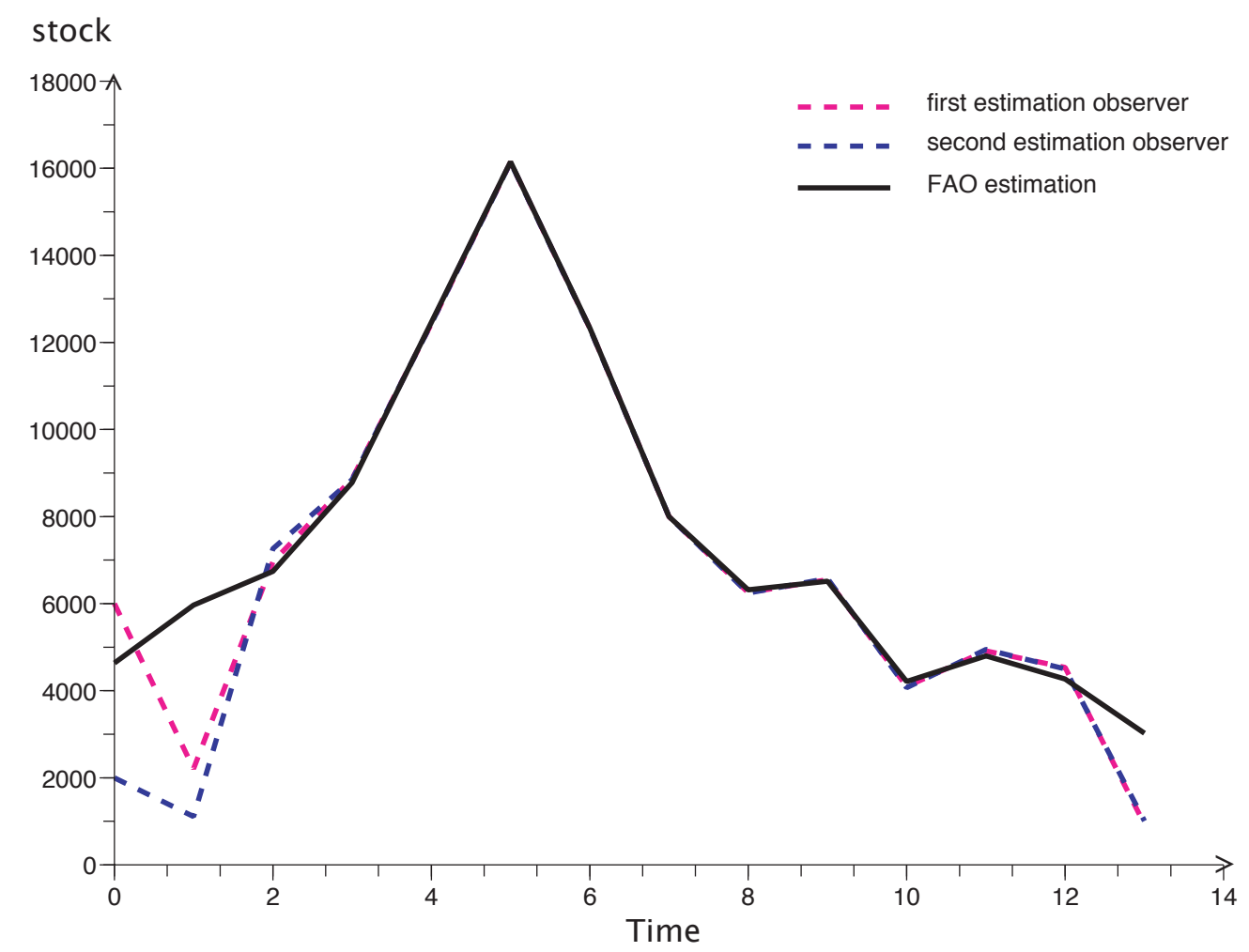

Figure 6: FAO estimates and the observer estimates for age class 1 


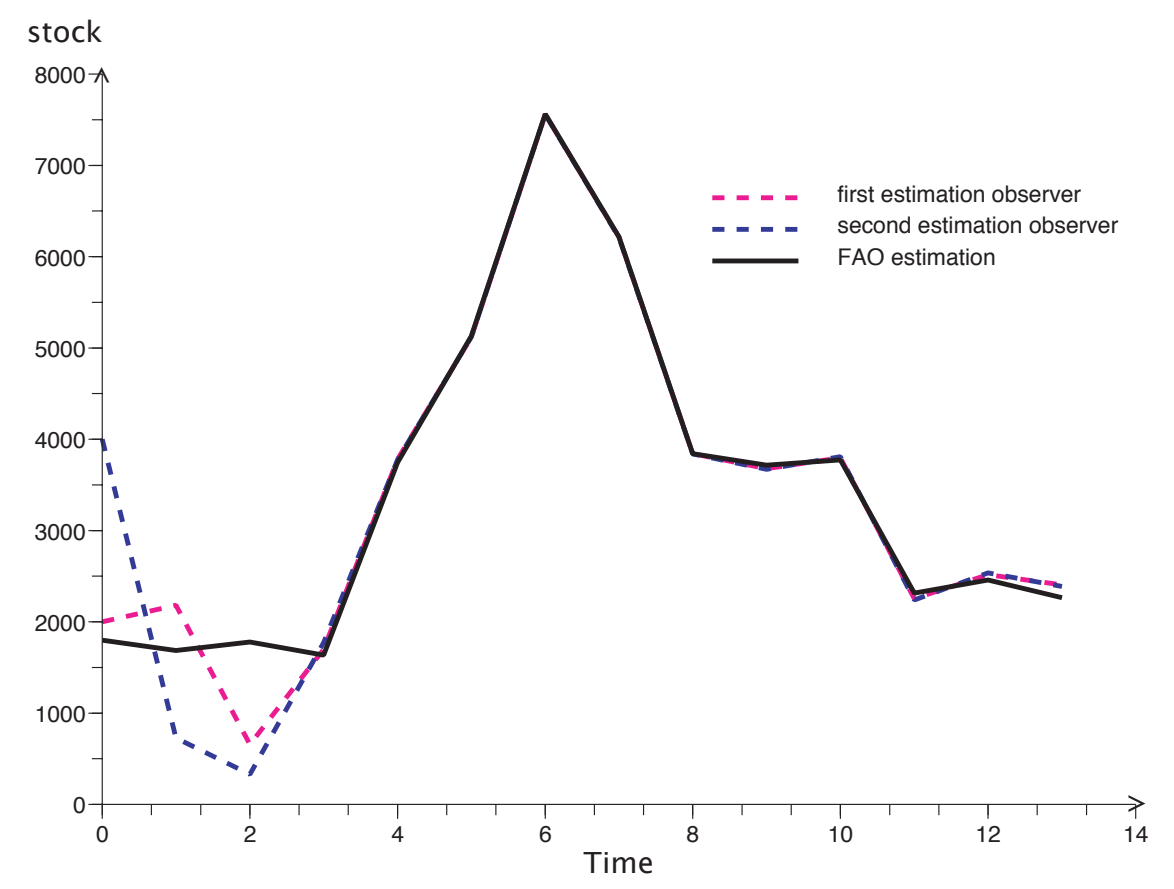

Figure 7: FAO estimates and the observer estimates for age class 2

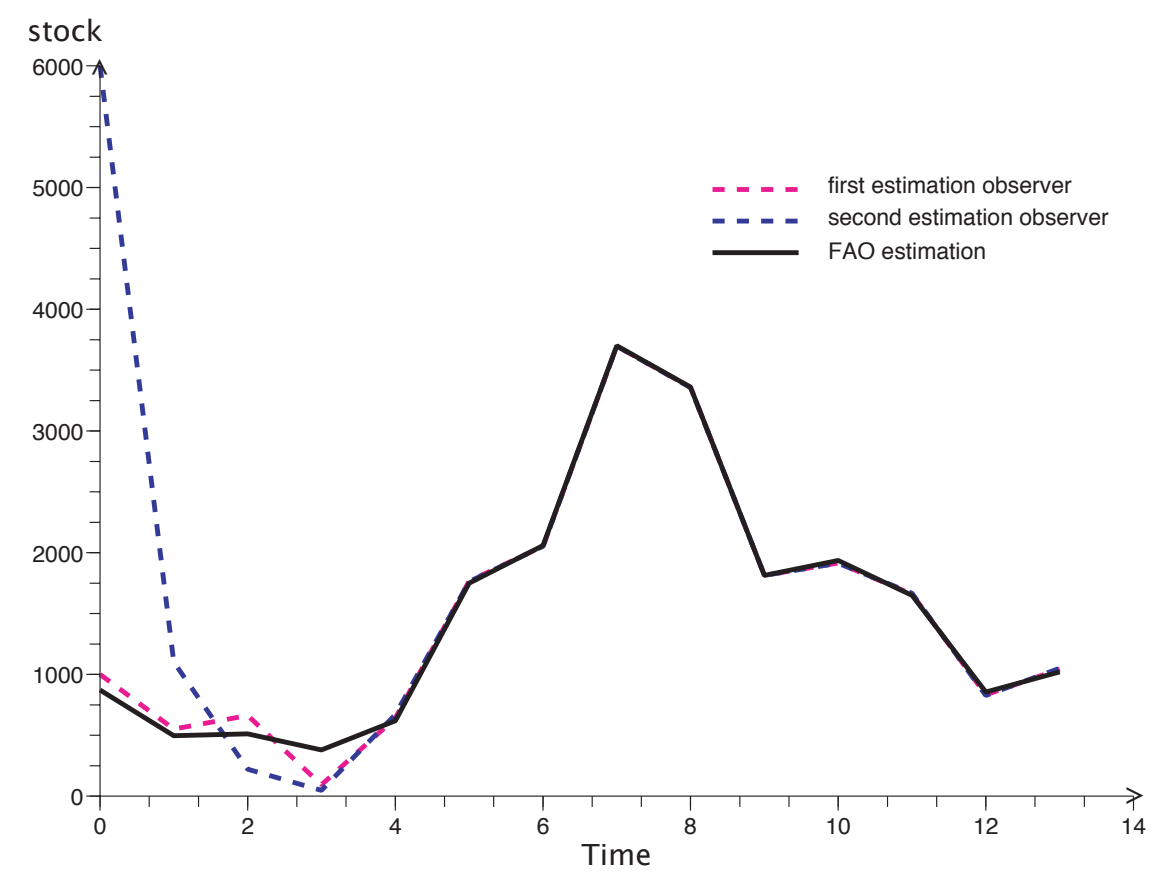

Figure 8: FAO estimates and the observer estimates for age class 3 


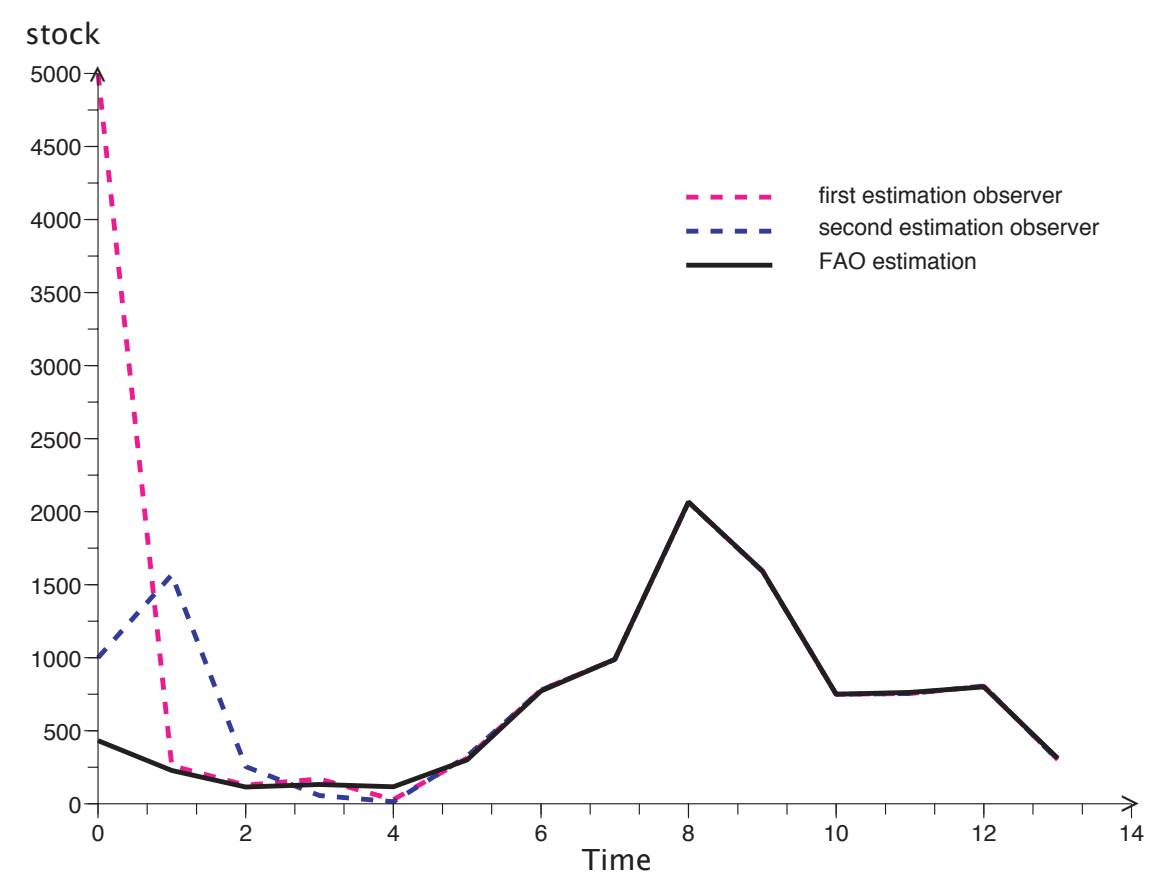

Figure 9: FAO estimates and the observer estimates for age class 4

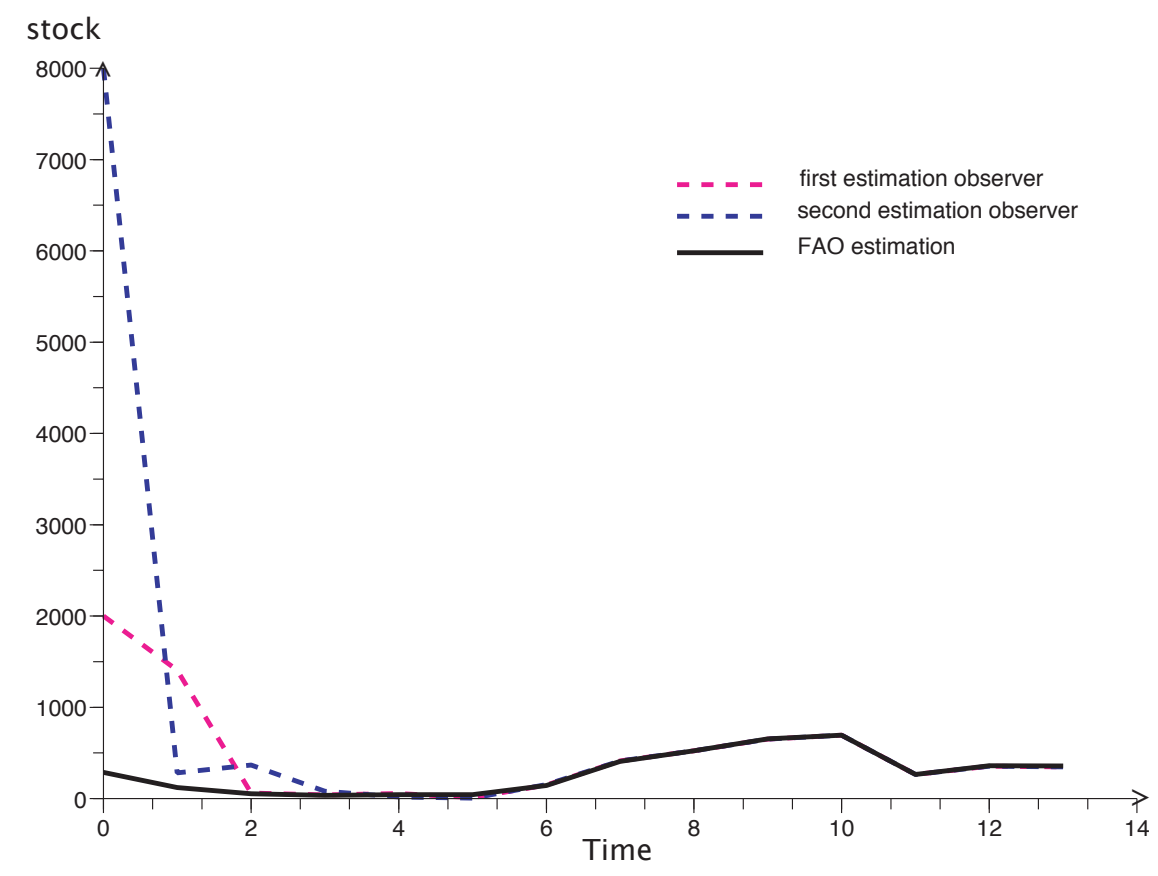

Figure 10: FAO estimates and the observer estimates for age class 5 


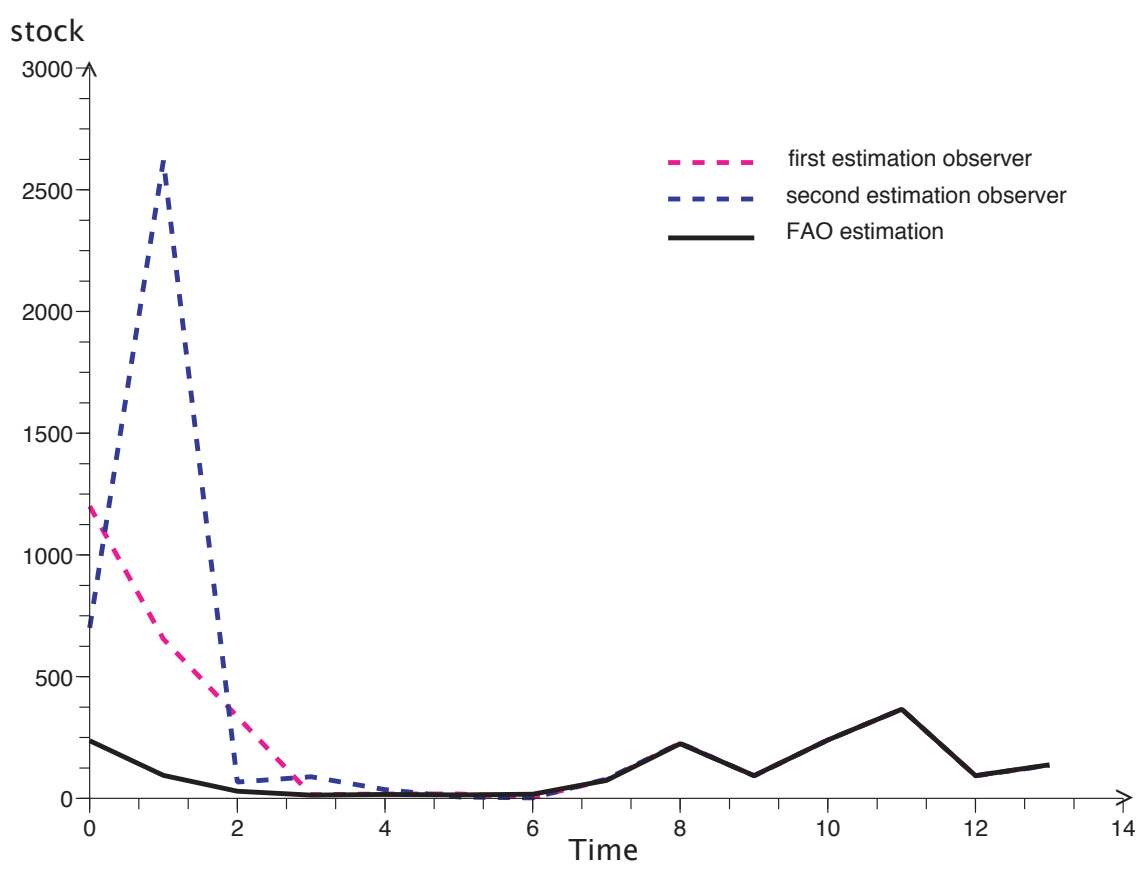

Figure 11: FAO estimates and the observer estimates for age class 6

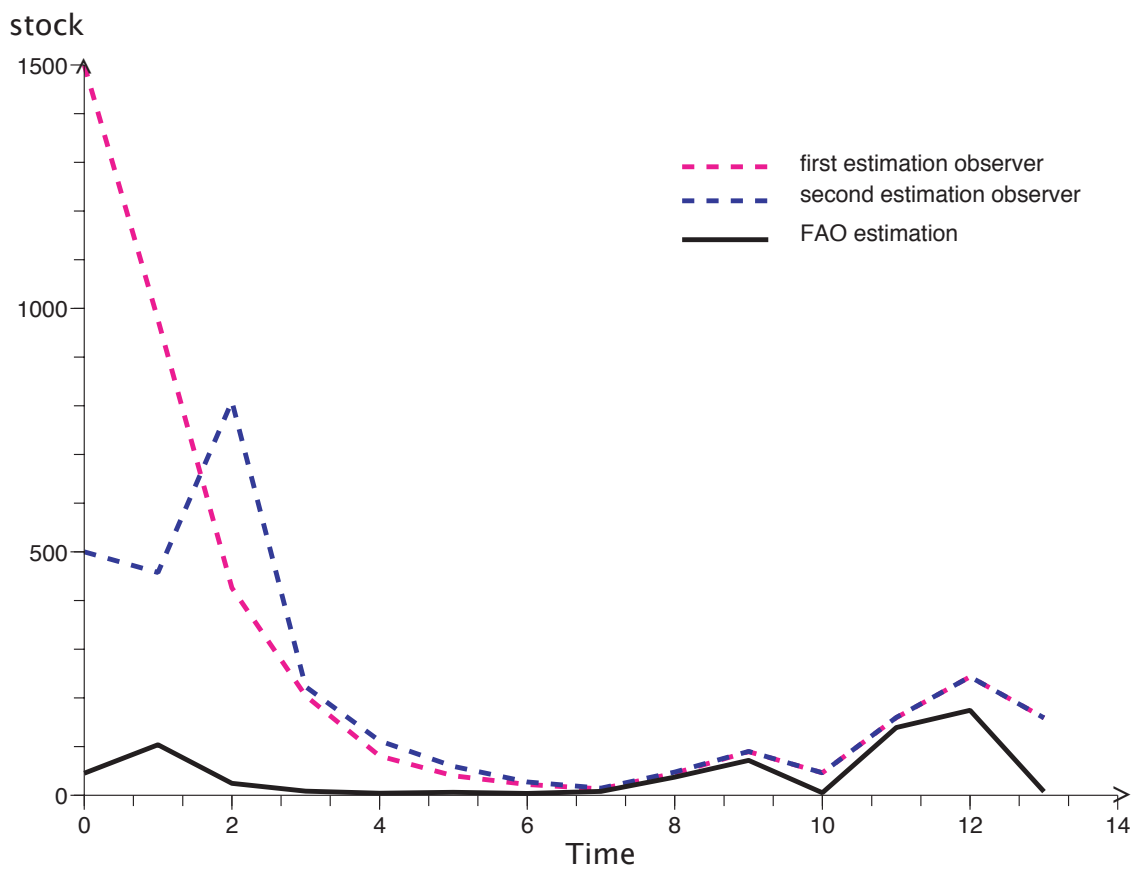

Figure 12: FAO estimates and the observer estimates for age class 7 


\section{Discussion}

We have applied the observer (16 or 20) given by the stage-class structured model to a fish population structured in immature and mature classes. The observer is implemented with an arbitrary initial condition and delivers stock estimates for immature and mature classes for each year. These estimates are comparable to those of the ICES. However the observer (20) slightly overestimates the biomass of the immature stage. This mild difference may be due to the difference between our estimation method and the ICES estimation method. It could also be due to the value we have used for the parameter $p$ (the proportion of individuals in immature class that moves to the mature class after one year) which is not given in the ICES report, we have used

$p=0.1$. In spite of this, the observer gives a good information about the fluctuation of the stock for the two stages during the considered period.

We have also applied the observer (22) to estimate the stock state for a harvested population structured in seven age-classes. The data corresponding to this population are given in a FAO report. We point out with simulations that even in choosing an initial condition of the observer very distant from the initial condition of the FAO estimates, the curve of the observer converges (quite rapidly) towards the curve of the FAO estimates. We also note that if we consider two different initial conditions of the observer, the two curves of the observer converge simultaneously toward the the graph of FAO estimates. Hence, in the absence of the FAO stock estimation, the states of the stock fish population are reached as soon as a curve of the observer reaches another curve of the observer with a different initial condition.

It must be noticed that for the applications with real data, we only need the value of the total catch for the whole population: the observer implementation does not require the knowledge of the captures for each stage.

When the analytic expression of the fishing effort as well as the the parameter numerical values are available it is possible to check the uniform observability condition and hence to compute the matrix gain $L(k)$ in order to increase the convergence of the estimation error towards zero. We think that when the computation of such $L(k)$ is possible, the convergence of the observer will be guaranteed without the condition of Proposition 2 concerning the minimal fishing effort value. A work in this direction is in progress.

\section{Conclusion}

We have built an observer for a stage-structured model of a harvested fish population. The model we have considered is a dynamical discrete-time system including a nonlinear recruitment relationship. We have shown how to use the catch data in order to give an estimate of the stock of each stage-class for the harvested fish population under consideration. The observer estimator has the particularity of not using the recruitment function which is very poorly known. It may be noticed that the observer we have built is easy to implement and it has been successfully tested by some real data from FAO and ICES Advisory Committee on fisheries Management. Historically, the tools and techniques of automatic control theory have been developed for artificial engineering systems but nowadays they are more and more applied to "natural systems". The work we address 
in this paper is an example showing how observer theory and computer sciences can be helpful for good policies in management fishery.

\section{Acknowledgments}

We thank the anonymous referees for their comments and suggestions that have allowed us to improve the presentation of this article.

\section{Appendix A: Proof of proposition 2}

We prove that system (15) is a global exponential observer for model $(7)$. Let $e(k)=x(k)-\hat{x}(k)$ be the error estimation at time $k$. It satisfies the equation:

$$
e(k+1)=\bar{A}(k) e(k)
$$

It's sufficient to prove that there exists $\delta$ such that $\|\bar{A}(k)\| \leq \delta<1$, for some matrix norm. Here we shall use the norm 1 defined by $\|\bar{A}(k)\|_{1}=\max _{j} \sum_{i=1}^{n}\left|\bar{a}_{i j}(k)\right|$. Using the construction of the matrix $\bar{A}(k)$, we can write

$$
\begin{gathered}
\|\bar{A}(k)\|_{1}=\left\|\left(I_{n \times n}-D(C(k+1) D)^{-1} C(k+1)\right) A(k)\right\|_{1}=\left\|I_{n \times n}-\frac{1}{C_{1}(k+1)} D C(k+1) A(k)\right\|_{1} \\
\|\bar{A}(k)\|_{1} \leq\left\|I_{n \times n}-\frac{1}{C_{1}(k+1)} D C(k+1)\right\|_{1}\|A(k)\|_{1}
\end{gathered}
$$

We have:

$$
\left\|I_{n \times n}-\frac{1}{C_{1}(k+1)} D C(k+1)\right\|_{1}=\max _{j}\left(\frac{C_{j}(k+1)}{C_{1}(k+1)}+1\right), \text { and }\|A(k)\|_{1}=\max _{j} s_{j}(k) .
$$

Hence:

$$
\|\bar{A}(k)\|_{1} \leq \max _{j}\left(\frac{C_{j}(k+1)}{C_{1}(k+1)}+1\right) \max _{j} s_{j}(k) .
$$

The remaining part of the proof is quite similar to the proof of the main result of [26]. We give it here in order to be self-contained.

For $j=1 \ldots n$, Let: $\gamma_{j}(k)=\frac{C_{j}(k+1)}{C_{1}(k+1)}$. 
We have:

$$
\begin{aligned}
\gamma_{j}(k)= & \frac{q_{j} E(k+1)\left(1-e^{\left(-M_{j}-q_{j} E(k+1)\right) \tau}\right)}{M_{j}+q_{j} E(k+1)} \frac{M_{1}+q_{1} E(k+1)}{q_{1} E(k+1)\left(1-e^{-\left(M_{1}-q_{1} E(k+1)\right) \tau}\right)} \\
\gamma_{j}(k)= & \frac{M_{1} q_{j}\left(1-e^{\left(-M_{j}-q_{j} E(k+1)\right) \tau}\right)}{q_{1}\left(M_{j}+q_{j} E(k+1)\right)\left(1-e^{\left(-M_{1}-q_{1} E(k+1)\right) \tau}\right)} \\
& +\frac{q_{j} q_{1} E(k+1)\left(1-e^{\left(-M_{j}-q_{j} E(k+1)\right) \tau}\right)}{q_{1}\left(M_{j}+q_{j} E(k+1)\right)\left(1-e^{\left(-M_{1}-q_{1} E(k+1)\right) \tau}\right)}
\end{aligned}
$$

Since $\frac{q_{j} q_{1} E(k+1)}{q_{1}\left(M_{j}+q_{j} E(k+1)\right)}<1$, we can write

$$
\gamma_{j}(k) \leq \frac{M_{1} q_{j}\left(1-e^{\left(-M_{j}-q_{j} E(k+1)\right) \tau}\right)}{q_{1}\left(M_{j}+q_{j} E(k+1)\right)\left(1-e^{\left(-M_{1}-q_{1} E(k+1)\right) \tau}\right)}+\frac{1-e^{\left(-M_{j}-q_{j} E(k+1)\right) \tau}}{1-e^{\left(-M_{1}-q_{1} E(k+1)\right)_{\tau}}}
$$

The map $x \mapsto \frac{1-e^{-x \tau}}{x}$ is decreasing, hence:

$$
\frac{1-e^{\left(-M_{j}-q_{j} E(k+1)\right) \tau}}{M_{j}+q_{j} E(k+1)} \leq \frac{1-e^{\left(-M_{\min }-q_{\min } E_{\min }\right) \tau}}{M_{\min }+q_{\min } E_{\min }}
$$

So we obtain:

$$
\gamma_{j}(k) \leq \frac{M_{\max } q_{\max }}{q_{1}} \frac{\left(1-e^{\left(-M_{\min }-q_{\min } E_{\min }\right) \tau}\right)}{M_{\min }+q_{\min } E_{\min }} \frac{1}{1-e^{\left(-M_{1}-q_{1} E(k+1)\right) \tau}}+\frac{1-e^{\left(-M_{j}-q_{j} E(k+1)\right) \tau}}{1-e^{\left(-M_{1}-q_{1} E(k+1)\right) \tau}}
$$

Since $0<e^{\left(-M_{j}-q_{j} E(k+1)\right) \tau} \leq 1$, we have $1-e^{\left(-M_{j}-q_{j} E(k+1)\right) \tau} \leq 1$. Therefore, we have for $j=1 \ldots n-1$,

$$
\gamma_{j}(k) \leq \frac{M_{\max } q_{\max }}{q_{1}} \frac{\left(1-e^{\left(-M_{\min }-q_{\min } E_{\min }\right) \tau}\right)}{M_{\min }+q_{\min } E_{\min }} \frac{1}{1-e^{\left(-M_{1}-q_{1} E(k+1)\right) \tau}}+\frac{1}{1-e^{\left(-M_{1}-q_{1} E(k+1)\right)_{\tau}}} .
$$

The map $x \mapsto \frac{1}{1-e^{-x \tau}}$ is decreasing; it follows that:

$$
\frac{1}{1-e^{\left(-M_{1}-q_{1} E(k+1)\right) \tau}} \leq \frac{1}{1-e^{\left(-M_{\min }-q_{\min } E_{\min }\right) \tau}}
$$


Therefore,

$$
\gamma_{j}(k) \leq \frac{M_{\max } q_{\max }}{q_{1}} \frac{1}{M_{\min }+q_{\min } E_{\min }}+\frac{1}{1-e^{\left(-M_{\min }-q_{\min } E_{\min }\right) \tau}}, \forall j=1, \ldots, n .
$$

Otherwise $s_{i}(k) \leq e^{-M_{m i n}-q_{m i n} \tau E_{m i n}} \leq e^{\left(-M_{m i n}-q_{m i n} E_{m i n}\right) \tau}, \forall j=1, \ldots, n$.

Hence:

$$
\|\bar{A}(k)\|_{1} \leq\left(\frac{M_{\max } q_{\max }}{q_{1}} \frac{1}{M_{\min }+q_{\min } E_{\min }}+\frac{1}{1-e^{\left(-M_{\min }-q_{\min } E_{\min }\right) \tau}}+1\right) e^{\left(-M_{\min }-q_{\min } E_{\min }\right) \tau} .
$$

We denote:

$$
\delta\left(E_{\min }\right)=\left(\frac{M_{\max } q_{\max }}{q_{1}} \frac{1}{M_{\min }+q_{\min } E_{\min }}+\frac{1}{1-e^{\left(-M_{\min }-q_{\min } E_{\min }\right) \tau}}+1\right) e^{\left(-M_{\min }-q_{\min } E_{\min }\right) \tau} .
$$

We will show now that there exists $\eta>0$ in such a way that $E_{\min }>\eta \operatorname{implies} \delta\left(E_{\min }\right)<1$. Let $X=e^{\left(-M_{\min }-q_{\min } E_{\min }\right) \tau}$ and consider

$$
P(X)=-\frac{\tau M_{\max } q_{\max } X}{q_{1} \log (X)}+\frac{X}{1-X}+X-1 .
$$

One can remark that $P(X)=\delta\left(E_{\text {min }}\right)-1$.

We have $\lim _{X \rightarrow 0} P(X)=-1$ and $\lim _{X \rightarrow 1^{-}} P(X)=+\infty$. So there exists $\left.x_{1} \in\right] 0,1\left[\right.$ such that $P\left(x_{1}\right)=0$. Let $x^{*}=\inf \{x \in] 0,1[/ P(x)=0\}$ then we have $P(X)<0$ for all $X$ satisfying $0<X<x^{*}$. Now, $0<X<x^{*}$ is equivalent to $E_{\min }>\frac{-\log \left(x^{*}\right)}{q_{\min } \tau}-\frac{M_{\min }}{q_{\min }}$ since $X=e^{\left(-M_{\min }-q_{\min } E_{\min }\right) \tau}$. It is then sufficient to choose $\eta=\frac{-\log \left(x^{*}\right)}{q_{\min } \tau}-\frac{M_{\min }}{q_{\min }}$ and this completes the proof of Proposition 2.

\section{References}

[1] P. Albertos, Block multirate Input-Output model for sampled-Data control systems. IEEE Transactions on Automatic Control, vol 35 :1085-1088, 1990.

[2] B. D. O. Anderson and J. B. Moore, Optimal filering. Prentice Hall, Englewood Cliffs, NJ, 1979 .

[3] B. D. O. Anderson and J. B. Moore. Detectability and stabilizability of time-varying discretetime linear systems. SIAM Journal on Control and Optimization, 19(1):20-32, 1981.

[4] Anon(2001), Advisory Committee on Fisheries Management (ACFM): Report of the Arctic fisheries Working Group. ICES CM 2001/ACFM:19. 
[5] J. S. Baras, A. Bensoussan and M. R. James, Dynamic observers as asymptotic limits of recursive filters : special cases. SIAM Journal on Applied Mathematics, vol 48, No 5:11471158, 1988.

[6] R.J.H. Beverton, and S. J,. Holt 1957 On the dynamics of exploited fish populations. Chapman \& Hall.

[7] S.P. Bhattacharyya, Observer design for linear system with unknown inputs. IEEE Transactions on Automatic Control, 23:483-484, 1978.

[8] M. Boutayeb and M. Darouach. Observers design for linear time-varying systems. In 39th IEEE CDC, pages 3183-3187, 2000.

[9] G. F. Corliss, Survey of interval algorithms for ordinary differential equations. Appl. Math. Comput, vol 31: 112-120, 1989.

[10] M. Darouach, M. Zasadzinski and S.J. Xu, Full-order observer for linear systems with unknown inputs IEEE Transactions on Automatic Control,vol 39, No 3:606-609, 1994.

[11] FAO, Rapport du deuxième groupe de travail AD HOC sur les Chinchards et les Maquereaux de la zone nord du COPACE, Organisation des Nations Unies pour l'Alimentation et l'Agriculture. ROME, 1987. http://www.fao.org/DOCREP/003/S4882F/S4882F09.htm

[12] W. M. Getz and R. G. Haight. Population harvesting. Demographic models of fish, forest, and animal resources, volume 27 of Monographs in Population Biology. Princeton University Press, Princeton, NJ, 1989.

[13] M. Hou and P.C. Muller, Disturbance decoupled observer design: A unified viewpoint. IEEE Transactions on Automatic Control,vol 39, No 6:1338-1341, 1994.

[14] M. Hou and P.C. Muller, Design of observers for linear systems with unknown inputs. IEEE Transactions on Automatic Control, 37:872-875, 1992.

[15] G. Hostetter and J. Meditch, Observing systems with unmeasurable inputs. IEEE Transactions on Automatic Control, vol 18: 307-308, 1973.

[16] A. Iggidr, Controllability, observability and stability of mathematical models, in Mathematical Models. In Encyclopedia of Life Support Systems (EOLSS). Ed. Jerzy A. Filar. Developed under the auspices of the UNESCO, Eolss Publishers, Oxford,UK,? [http://www.eolss.net].

[17] L. Jaulin, I. Braems, M. Kieffer and E. Walter, Guaranteed nonlinear estimation using constraint propagation on sets. Int. J. Control, vol 74 No 18:1772-1782, 2001.

[18] J. Jin, M.J. Tank and C. Park, Time-delayed state and unknown input observation Int. J. Control, vol 66 No 5:733-745, 1997. 
[19] C. Johnson, An observers for systems with unknown and inacessible inputs. IEEE Transactions on Automatic Control, vol 21: 825-831, 1975.

[20] E. W. Kamen, Block form observers for linear time-varying discrete-time systems. Proc. IEEE Conference on Decision and Control, San Antonio, USA :355-356, 1993.

[21] E. W. Kamen, Study of linear time-varying discrete-time systems in terms of time-compressed models. Proc. IEEE Conference on Decision and Control, USA :3070-3075, 1992.

[22] A. Kurzhanski and I. Valyi, Ellipsoidal Calculus for Estimation and Control. Birkhuser, Boston, MA, 1997.

[23] D. G. Luenberger. An introduction to observers. IEEE Transactions on Automatic Control, AC-16(6):596-602, 1971.

[24] P. Magal and D. Pelletier. A fixed point theorem with application to a model of population dynamics. J. Difference Equ. Appl., 3(1):65-87, 1997.

[25] J.B. Moore and B.D.O. Anderson. Coping with singular transition matrices in estimation and control stability theory. Int. J. Control, 31:571-586, 1980.

[26] D. Ngom, A. Iggidr, A. Guiro and A. Ouahbi. An Observer for a nonlinear Age-structured model of a Harvested Fish Population . Mathematical Biosciences and Engineering, 5(2):337$354,2008$.

[27] R. Nikoukhah, S. L. Campbell and F. Delebecque. Observer Design for General Linear Timeinvariant Systems. Automatica,vol 34, No 3: 575-583, 1998.

[28] A. Rapaport and J. L. Gouzé. Parallelotopic and practical observers for non-linear uncertain systems. International journal of control.,vol 76, No 3: 237-251, 2003.

[29] R. Rihm. interval methods for initial value problems in ODEs. Topics in Validated Computations, Elsevier Science B. V, 173-208, 1994.

[30] W. E. Ricker. Stock and recruitment. J. Fish. Res. Board Can., 11:559-623, 1954.

[31] J. G. Shepherd, A family of general production curves for exploited populations. Mathematical Biosciences, 59:77-93, 1982.

[32] F. C. Sheweppe, Recursive state estimation: Unknown but bounded errors and systems inputs. IEEE Transactions on Automatic Control,vol 13, no 1:22-28, 1968.

[33] S. Sundaram and C.N. Hadjicostis, Delays observers for linear systems with unknown inputs IEEE Transactions on Automatic Control, 52:334-339, 2007.

[34] E. D. Sontag, Mathematical control theory. Deterministic finite-dimensional systems, volume 6 of Texts in Applied Mathematics. Springer-Verlag, New York, 1998. 
[35] M.E. Valcher, State observers for discrete-time linear systems with unknown inputs. IEEE Transactions on Automatic Control, vol 44, No 2:397-401, 1999.

[36] A. Wikan and A. Eide, An Analysis of a Nonlinear Stage-Structured Cannibalism Model with Application to the Northeast Arctic Cod Stock, Bulletin of Mathematical Biology, 66, 2004, 1685-1704.

[37] F. Yang and R. W. Wilde, Observers for linear systems with unknown inputs. IEEE Transactions on Automatic Control, vol 20, 716-717, 1975.

[38] S. H. Wang, E. Davison and P. Dorato, Observing the states of systems with unmeasurable disturbances. IEEE Transactions on Automatic Control, vol 33, No 7:677-681, 1988. 


\section{ICES data}

Table 1: Table: Biomass and catch in million tonnes of the Arctic cod in the North-East between 1946 and 2000. These data are from the "ICES Advisory Committee on Fisheries Management" (Anon, 2001), table 3.7 (catch), table 3.19 (biomass) and table 3.23 (maturity).

\begin{tabular}{|c|c|c|c|c|c|c|}
\hline \multicolumn{2}{|c|}{$\begin{array}{c}\text { ICES Biomass } \\
\text { estimates } \\
\text { (million tonnes) }\end{array}$} & $\begin{array}{c}\text { Catch } \\
\text { (million tonnes) }\end{array}$ & \multicolumn{2}{c|}{$\begin{array}{c}\text { Fishing mortality } \\
\text { rate }\end{array}$} \\
\hline $\begin{array}{c}\text { Year } \\
(\mathrm{k})\end{array}$ & $\begin{array}{c}\text { Immature } \\
\left(m_{1}(k)\right)\end{array}$ & $\begin{array}{c}\text { Mature } \\
\left(m_{2}(k)\right)\end{array}$ & $\begin{array}{c}\text { Immature } \\
\left(y_{1}(k)\right)\end{array}$ & $\begin{array}{c}\text { Mature } \\
\left(y_{2}(k)\right)\end{array}$ & $\begin{array}{c}\text { Immature } \\
\left(F_{1}(k)\right)\end{array}$ & $\begin{array}{c}\text { Mature } \\
\left(F_{2}(k)\right)\end{array}$ \\
\hline 1946 & 3.3866 & 1.1206 & 0.4222 & 0.2633 & 0.1247 & 0.2350 \\
1947 & 2.7283 & 1.1740 & 0.4959 & 0.4688 & 0.1818 & 0.3993 \\
1948 & 2.8562 & 1.0264 & 0.5176 & 0.3510 & 0.1812 & 0.3420 \\
1949 & 2.5528 & 0.7360 & 0.5503 & 0.2563 & 0.2156 & 0.3482 \\
1950 & 2.5292 & 0.6206 & 0.4284 & 0.2444 & 0.1694 & 0.3938 \\
& & & & & & \\
\hline 1951 & 3.0474 & 0.5741 & 0.5263 & 0.1940 & 0.1727 & 0.3379 \\
1952 & 3.4114 & 0.5271 & 0.6951 & 0.2428 & 0.2038 & 0.4606 \\
1953 & 3.8533 & 0.4010 & 0.5209 & 0.1425 & 0.1352 & 0.3554 \\
1954 & 3.9139 & 0.4350 & 0.7196 & 0.1691 & 0.1839 & 0.3887 \\
1955 & 3.2905 & 0.3512 & 0.9268 & 0.1526 & 0.2817 & 0.4345 \\
1956 & 3.1074 & 0.3034 & 1.1425 & 0.1421 & 0.3677 & 0.4684 \\
1957 & 2.6487 & 0.2103 & 0.7023 & 0.0900 & 0.2651 & 0.4280 \\
1958 & 2.1979 & 0.1978 & 0.6019 & 0.0830 & 0.2739 & 0.4196 \\
1959 & 2.2912 & 0.4382 & 0.6197 & 0.1806 & 0.2705 & 0.4121 \\
1960 & 2.0169 & 0.3890 & 0.4343 & 0.1629 & 0.2153 & 0.4188 \\
& & & & & & \\
\hline
\end{tabular}




\begin{tabular}{|l|l|l|l|l|l|l|}
\hline 1961 & 2.1368 & 0.4104 & 0.5113 & 0.2026 & 0.2393 & 0.4937 \\
1962 & 1.9697 & 0.3167 & 0.5785 & 0.1574 & 0.2937 & 0.4970 \\
1963 & 1.7560 & 0.2118 & 0.6335 & 0.1257 & 0.3608 & 0.5935 \\
1964 & 1.3421 & 0.1892 & 0.3270 & 0.0989 & 0.2436 & 0.5227 \\
1965 & 1.6769 & 0.1036 & 0.2991 & 0.0458 & 0.1784 & 0.4421 \\
1966 & 2.7595 & 0.1224 & 0.3425 & 0.0499 & 0.1241 & 0.4077 \\
1967 & 3.2925 & 0.1318 & 0.4620 & 0.0628 & 0.1403 & 0.4765 \\
1968 & 3.2669 & 0.2306 & 0.9045 & 0.0914 & 0.2769 & 0.3964 \\
1969 & 2.7351 & 0.1546 & 1.0495 & 0.0886 & 0.3837 & 0.5731 \\
1970 & 1.9394 & 0.2281 & 0.7180 & 0.1175 & 0.3702 & 0.5151 \\
& & & & & & \\
\hline 1971 & 1.4845 & 0.3167 & 0.4008 & 0.1546 & 0.2700 & 0.4882 \\
1972 & 1.7130 & 0.3523 & 0.2886 & 0.1895 & 0.1685 & 0.5379 \\
1973 & 2.8488 & 0.3380 & 0.4363 & 0.1733 & 0.1532 & 0.5127 \\
1974 & 2.3150 & 0.1669 & 0.7231 & 0.0839 & 0.3124 & 0.5027 \\
1975 & 2.1793 & 0.1440 & 0.6522 & 0.0678 & 0.2993 & 0.4708 \\
1976 & 2.0396 & 0.1738 & 0.6082 & 0.0755 & 0.2982 & 0.4344 \\
1977 & 1.7767 & 0.3473 & 0.6734 & 0.1740 & 0.3790 & 0.5010 \\
1978 & 1.6184 & 0.2460 & 0.4947 & 0.1469 & 0.3057 & 0.5972 \\
1979 & 1.0343 & 0.1778 & 0.2649 & 0.0980 & 0.2561 & 0.5512 \\
1980 & 0.8233 & 0.1102 & 0.2400 & 0.0590 & 0.2915 & 0.5354 \\
& & & & & & \\
\hline 1981 & 0.8910 & 0.1699 & 0.2437 & 0.0942 & 0.2735 & 0.5544 \\
1982 & 0.4938 & 0.3315 & 0.1283 & 0.1622 & 0.2598 & 0.4893 \\
1983 & 0.4865 & 0.3328 & 0.1323 & 0.1916 & 0.2719 & 0.5757 \\
1984 & 0.7402 & 0.2556 & 0.1484 & 0.1444 & 0.2005 & 0.5649 \\
1985 & 0.9909 & 0.1966 & 0.2047 & 0.0977 & 0.2066 & 0.4969 \\
1986 & 1.5661 & 0.1731 & 0.3319 & 0.0914 & 0.2119 & 0.5280 \\
1987 & 1.1331 & 0.1203 & 0.4392 & 0.0724 & 0.3876 & 0.6018 \\
1988 & 0.8044 & 0.2053 & 0.3171 & 0.1178 & 0.3942 & 0.5738 \\
1989 & 0.7770 & 0.1970 & 0.2461 & 0.0904 & 0.3167 & 0.4589 \\
1990 & 0.7320 & 0.3446 & 0.1112 & 0.0985 & 0.1519 & 0.2858 \\
& & & & & & \\
\hline
\end{tabular}




\begin{tabular}{|l|l|l|l|l|l|l|}
\hline 1991 & 1.0702 & 0.6847 & 0.1425 & 0.1927 & 0.1332 & 0.2814 \\
1992 & 1.3533 & 0.8847 & 0.2037 & 0.2960 & 0.1505 & 0.3346 \\
1993 & 2.0052 & 0.7461 & 0.2974 & 0.2769 & 0.1483 & 0.3711 \\
1994 & 1.9007 & 0.6137 & 0.4394 & 0.3248 & 0.2312 & 0.5292 \\
1995 & 1.6134 & 0.5093 & 0.4738 & 0.2640 & 0.2937 & 0.5184 \\
1996 & 1.3109 & 0.5804 & 0.4360 & 0.2856 & 0.3326 & 0.4921 \\
1997 & 1.2144 & 0.5763 & 0.4373 & 0.3248 & 0.3431 & 0.5636 \\
1998 & 1.2146 & 0.3961 & 0.3558 & 0.2326 & 0.2929 & 0.5872 \\
1999 & 1.0585 & 0.2645 & 0.3388 & 0.1477 & 0.3201 & 0.5584 \\
2000 & 1.0854 & 0.2264 & 0.2836 & 0.1285 & 0.2613 & 0.5676 \\
& & & & & & \\
\hline
\end{tabular}


FAO data (from http://www.fao.org/DOCREP/003/S4882F/S4882F09.htm).

Table 2: Trachurus spp.: Catch in $10^{6}$ of individuals by age classes.

\begin{tabular}{|c|c|c|c|c|c|c|c|c|c|}
\hline \multirow[t]{2}{*}{ Years } & \multicolumn{7}{|c|}{ age } & \multirow{2}{*}{$\begin{array}{l}\text { Total catch } \\
(1000 \mathrm{t})\end{array}$} & \multirow{2}{*}{$\begin{array}{c}\text { Total catch } \\
10^{6} \text { individuals }\end{array}$} \\
\hline & 1 & 2 & 3 & 4 & 5 & 6 & $7+$ & & \\
\hline 1972 & 1492.0 & 798.1 & 403.9 & 188.0 & 106.4 & 52.0 & 18.5 & 390.123 & 3058.9 \\
\hline 1973 & 2457.0 & 680.9 & 250.9 & 114.5 & 60.3 & 43.2 & 48.5 & 383.052 & 3625.3 \\
\hline 1974 & 3273.2 & 947.3 & 240.4 & 44.9 & 26.2 & 12.3 & 11.8 & 414.63 & 4562.8 \\
\hline 1975 & 2078.1 & 493.6 & 152.3 & 48.9 & 7.7 & 4.8 & 2.6 & 302.317 & 2803.9 \\
\hline 1976 & 3202.3 & 685.6 & 97.4 & 35.6 & 16.3 & 4.6 & 1.1 & 394.145 & 4060.3 \\
\hline 1977 & 2927.2 & 1391.2 & 380.3 & 52.1 & 12.0 & 6.3 & 1.4 & 392.572 & 4787.6 \\
\hline 1978 & 1650.4 & 1162.8 & 338.7 & 78.2 & 16.5 & 3.0 & 0.5 & 294.151 & 3268.1 \\
\hline 1979 & 1323.3 & 534.7 & 231.0 & 99.0 & 29.6 & 10.0 & 0.8 & 223.165 & 2246.1 \\
\hline 1980 & 150.2 & 676.6 & 582.1 & 799.6 & 306.6 & 86.0 & 11.4 & 503.081 & 2619.6 \\
\hline 1981 & 230.4 & 415.2 & 462.2 & 357.9 & 207.2 & 72.6 & 14.1 & 357.935 & 1764.0 \\
\hline 1982 & 310.5 & 840.4 & 542.4 & 254.1 & 71.5 & 8.1 & 1.1 & 310.464 & 2045.5 \\
\hline 1983 & 591.1 & 727.3 & 262.9 & 135.9 & 88.4 & 62.5 & 31.8 & 280.000 & 1886.6 \\
\hline 1984 & 424.6 & 621.4 & 274.9 & 167.1 & 105.7 & 68.4 & 41.9 & 300.000 & 1680.6 \\
\hline 1985 & 145.6 & 800.1 & 360.3 & 109.8 & 126.4 & 48.7 & 2.5 & 320.000 & 1609.4 \\
\hline
\end{tabular}


Table 3: Fishing mortality rates. $(\mathrm{M}=$ natural mortality rate=0.5).

\begin{tabular}{|l|c|c|c|c|c|c|c|}
\hline \multirow{2}{*}{ Years } & \multicolumn{7}{|c|}{ age-classes } \\
\cline { 2 - 8 } & 1 & 2 & 3 & 4 & 5 & 6 & $7+$ \\
\hline 1972 & 0.511725 & 0.788882 & 0.841723 & 0.767820 & 0.616278 & 0.322343 & 0.705246 \\
\hline 1973 & 0.710480 & 0.691405 & 0.962460 & 0.953076 & 0.933614 & 0.833445 & 0.850099 \\
\hline 1974 & 0.911205 & 1.462620 & 0.858620 & 0.660721 & 0.921245 & 0.740458 & 0.879356 \\
\hline 1975 & 0.351619 & 0.472105 & 0.686220 & 0.617037 & 0.312602 & 0.620453 & 0.488036 \\
\hline 1976 & 0.387599 & 0.261425 & 0.221046 & 0.483193 & 0.632487 & 0.445506 & 0.397193 \\
\hline 1977 & 0.258610 & 0.413621 & 0.318220 & 0.245832 & 0.424763 & 0.816728 & 0.332598 \\
\hline 1978 & 0.184893 & 0.215220 & 0.232136 & 0.136975 & 0.167873 & 0.248101 & 0.185781 \\
\hline 1979 & 0.233446 & 0.115179 & 0.082385 & 0.135158 & 0.096253 & 0.187148 & 0.132838 \\
\hline 1980 & 0.030647 & 0.250393 & 0.245816 & 0.651817 & 1.229370 & 0.641243 & 0.481579 \\
\hline 1981 & 0.045911 & 0.152152 & 0.383773 & 0.330540 & 0.502452 & 2.385422 & 0.283060 \\
\hline 1982 & 0.098016 & 0.327470 & 0.430687 & 0.546851 & 0.139337 & 0.043822 & 0.308936 \\
\hline 1983 & 0.168887 & 0.496638 & 0.224000 & 0.253589 & 0.540531 & 0.241525 & 0.337494 \\
\hline 1984 & 0.134262 & 0.380006 & 0.511330 & 0.341390 & 0.457392 & 0.010983 & 0.357427 \\
\hline 1985 & 0.063021 & 0.577001 & 0.577000 & 0.577000 & 0.577000 & 0.577000 & 0.530840 \\
\hline
\end{tabular}

Table 4: Abundance (FAO estimates) in millions individuals per age class and total biomass in thousand tons.

\begin{tabular}{|c|c|c|c|c|c|c|c|c|c|}
\hline \multirow[t]{2}{*}{ Years } & \multicolumn{8}{|c|}{ age-classes } & \multirow{2}{*}{$\begin{array}{c}\text { Total } \\
\text { Biomass } \\
(1000 \mathrm{t})\end{array}$} \\
\hline & $0+$ & 1 & 2 & 3 & 4 & 5 & 6 & $7+$ & \\
\hline 1972 & 9836.6 & 4635.1 & 1800 & 871.7 & 432 & 286.6 & 236.6 & 45.1 & 1191.9 \\
\hline 1973 & 11053.1 & 5966.2 & 1685.3 & 496 & 227.9 & 121.6 & 93.9 & 104 & 1066.5 \\
\hline 1974 & 15718.7 & 674.1 & 1779 & 512 & 114.9 & 53.3 & 29 & 24.7 & 1080.9 \\
\hline 1975 & 21772 & 8779.6 & 1634.8 & 379 & 131.6 & 36 & 12.9 & 8.4 & 1273.9 \\
\hline 1976 & 30610.6 & 12463.9 & 3746.5 & 618.4 & 115.7 & 43.1 & 16 & 4.2 & 1929.9 \\
\hline 1977 & 20373.3 & 16140.9 & 5130.7 & 1749.6 & 300.7 & 43.3 & 13.9 & 6.2 & 2360.9 \\
\hline 1978 & 13264.6 & 12329.1 & 7563.3 & 2057.8 & 771.9 & 142.6 & 17.2 & 3.7 & 2441.4 \\
\hline 1979 & 10411.7 & 7999.2 & 6215.7 & 3699.1 & 989.5 & 408.2 & 73.9 & 8.1 & 2455.6 \\
\hline 1980 & 10737.7 & 6315 & 3841.6 & 3359.8 & 2066.2 & 524.3 & 224.9 & 37.2 & 2488.7 \\
\hline 1981 & 6939.1 & 6512.7 & 3714.7 & 1813.9 & 1593.7 & 653 & 93 & 71.8 & 2024.3 \\
\hline 1982 & 7913.9 & 4208.8 & 3772.9 & 1935 & 749.6 & 694.5 & 239.7 & 5.2 & 1738.6 \\
\hline 1983 & 7041.2 & 4800 & 2314.4 & 1649.3 & 763 & 263.1 & 366.5 & 139.1 & 1533.4 \\
\hline 1984 & 6000 & 4270.7 & 2458.9 & 854.5 & 799.6 & 359.1 & 93 & 174.6 & 1290.9 \\
\hline 1985 & 7300 & 3021.4 & 2264.9 & 1019.9 & 310.8 & 357.8 & 137.9 & 7.5 & 1037.3 \\
\hline
\end{tabular}

